University of Rhode Island

DigitalCommons@URI

Open Access Master's Theses

2016

\title{
The Impact of the Healthy Children, Healthy Families Curriculum on Maternal Food Parenting Practices
}

Laura E. Otterbach

University of Rhode Island, laura_otterbach@uri.edu

Follow this and additional works at: https://digitalcommons.uri.edu/theses

\section{Recommended Citation}

Otterbach, Laura E., "The Impact of the Healthy Children, Healthy Families Curriculum on Maternal Food Parenting Practices" (2016). Open Access Master's Theses. Paper 887.

https://digitalcommons.uri.edu/theses/887

This Thesis is brought to you for free and open access by DigitalCommons@URI. It has been accepted for inclusion in Open Access Master's Theses by an authorized administrator of DigitalCommons@URI. For more information, please contact digitalcommons-group@uri.edu. 
THE IMPACT OF THE HEALTHY CHILDREN, HEALTHY FAMILIES CURRICULUM ON MATERNAL FOOD PARENTING PRACTICES

BY

LAURA E. OTTERBACH

A THESIS SUBMITTED IN PARTIAL FULFILLMENT OF THE

REQUIREMENTS FOR THE DEGREE OF

MASTER OF SCIENCE

IN

NUTRITION AND FOOD SCIENCES

UNIVERSITY OF RHODE ISLAND

2016 


\title{
MASTER OF SCIENCE THESIS
}

\author{
OF
}

\section{LAURA E. OTTERBACH}

APPROVED:

Thesis Committee:

$\begin{array}{ll}\text { Major Professor } & \text { Alison Tovar } \\ & \text { Geoffrey Greene } \\ & \text { Colleen Redding } \\ \text { Nasser H. Zawia } & \text { DEAN OF THE GRADUATE SCHOOL }\end{array}$

UNIVERSITY OF RHODE ISLAND

2016 


\begin{abstract}
Objective: To assess the impact of the evidence-based Healthy Children, Healthy

Families (HCHF) curriculum on changes in positive food parenting practices (FPPs).

Design/Setting: Non-experimental pre/post within-subjects design. The study primarily took place at a free healthcare clinic (Clinica Esperanza/Hope Clinic) located in Providence, RI.

Participants: Mother-child dyads were recruited from the community $(n=40)$ and completed baseline data measures for an 8-week group-based intervention, with 24 mother-child dyads completing the intervention. Dyads were primarily Hispanic, and of low socio-economic status.

Intervention: The 8-week, evidence-based HCHF curriculum/intervention was delivered primarily in Spanish to 4 separate groups of mothers by trained paraprofessional educators, or navegantes.
\end{abstract}

Main Outcome Measures: Mothers completed self-administered surveys pre/post which included demographic questions, seven subscales from the Comprehensive Feeding Practices Questionnaire, and the 16-item HCHF Behavior Checklist.

Analysis: Descriptive statistics and paired samples t-tests were used to analyze motherchild dyad data $(n=40)$.

Results: There were significant improvements in positive FPPs, including modeling and involvement, $(\mathrm{p}<0.05)$. There were also significant improvements in several mother and child diet and activity outcomes.

Conclusions and Implications: Positive FFPs, and mother and child health behaviors improved after participating in an 8-week group based intervention. Community-based 
delivery of the HCHF curriculum is feasible and may be effective in improving food parenting practices as well as behaviors that contribute to childhood obesity. 


\section{ACKNOWLEDGEMENTS}

My Master's thesis work during my two years at URI has been made possible by so many people and I would like to thank everyone involved or who has given me guidance throughout this process. In particular, I would like to thank my major advisor, Dr. Alison Tovar for her leadership and support throughout my graduate school experience, and for teaching me so much about community nutrition research. After starting at URI with minimal research experience, Dr. Tovar accepted me to work in her research lab which I am forever grateful for. I have learned so much from her expertise and I have had such a positive experience working with her these past two years. I would also like to thank the members of my thesis committee, Dr. Geoffrey Greene and Dr. Colleen Redding, and my defense chair Dr. Mary Greaney for their involvement in my thesis work and their support throughout the research process.

I also would like to say thank you to all of the NFS graduate students for creating such a positive learning environment, you all have made my experience at URI a memorable one. Thank you to all of you who supported me along the way whether it was offering your help or guidance or simply providing words of encouragement. I feel so lucky to have worked with all of you. A special thank you to the fellow graduate students I worked with in the CNCOP lab, Noereem, Megan, Amy, Maggie and Tayla. Thank you all for your guidance and encouragement. I also would like to thank each of the undergraduate students who helped in the CNCOP lab on my thesis work, in particular Margaret Garcia for her dedication to the project. Additionally, I would like to thank everyone at Clínica Esperanza/Hope Clinic for their support throughout my thesis work. 
Without the clinic's amazing navegantes and volunteers, my thesis work would not have been possible.

Thank you to everyone in the NFS department for their support during my time at URI. In particular, I would like to thank Dr. Geoffrey Greene for his guidance (and patience) while I completed the dietetic internship program, and Dr. Ingrid Lofgren for her support for the graduate students. Additionally, thank you to all URI professors that I worked with during my graduate coursework for instilling your knowledge and challenging me throughout my time in graduate school. The knowledge I have gained from all of you will be extremely valuable as I enter the professional world of dietetics. I would finally like to thank my family and friends for their support throughout the two hardest years of my life. It was a quite a challenge but overall an amazing and unforgettable experience. A huge thank you to my incredible support system; Eddie, Mom \& David, Dad \& Paula, Graham, Cary, Mr. and Mrs. Kilcline, and Nana. Your love and support kept me going these past two years, you all mean everything to me and I hope I've made each of you proud. 


\section{PREFACE}

This thesis was written to comply within the University of Rhode Island graduate school Manuscript Thesis Format. This thesis contains one manuscript: The Impact of the Healthy Children, Healthy Families Curriculum on Maternal Food Parenting Practices. This manuscript has been written in a form suitable for publication in the Journal of Nutrition Education and Behavior. 


\section{TABLE OF CONTENTS}

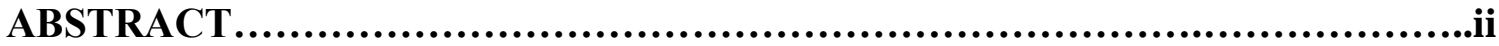

ACKNOWLEDGEMENTS ........................................................ iv

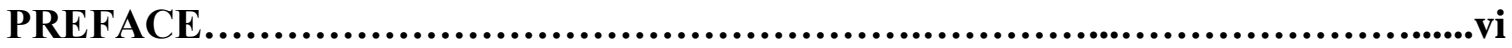

TABLE OF CONTENTS .......................................................... vii

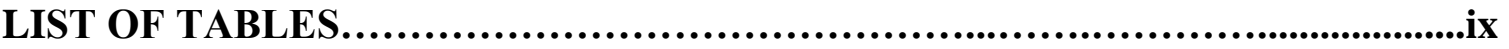

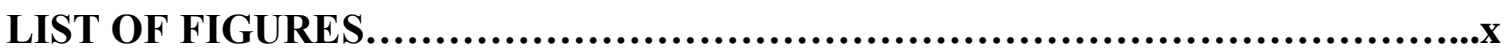

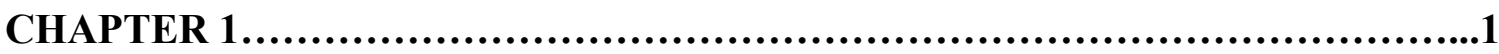

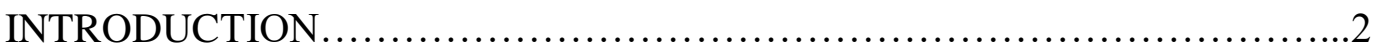

METHODOLOGY .......................................................... 6

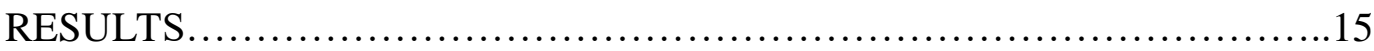

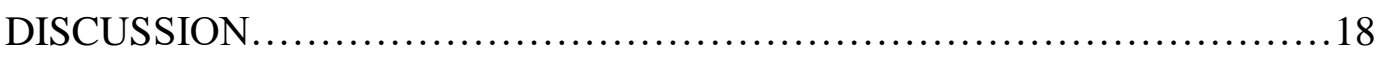

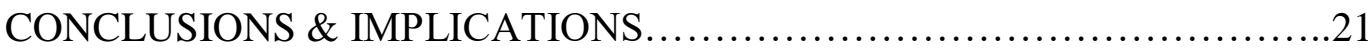

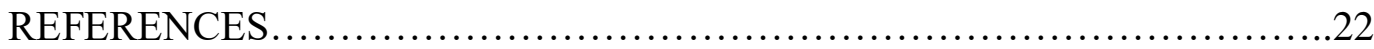

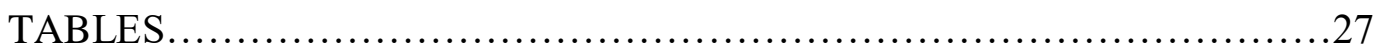

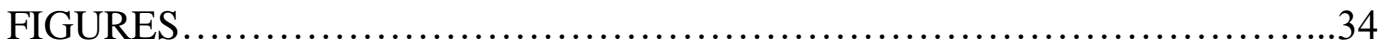

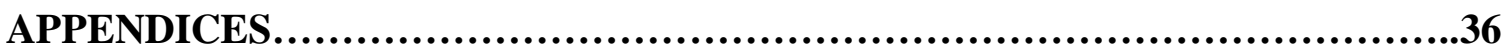

APPENDIX A: EXTENDED REVIEW OF THE LITERATURE..................36

APPENDIX B: EXTENDED METHODOLOGY .............................53

APPENDIX C: RECRUITMENT FLIER ..................................63

APPENDIX D: PATHS AND KEYS TO SUCCESS USED IN HCHF...........64

APPENDIX E: PARENTING PRACTICES ENCOURAGED IN HCHF.........65

APPENDIX F: EXAMPLE OF ACTIVE PLAY BREAK USED IN HCHF......66 
APPENDIX G: EXAMPLE OF HEALTHY RECIPE USED IN HCHF

APPENDIX H: OUTLINE OF WEEKLY PRIZES/INCENTIVES.............68

APPENDIX I: EXAMPLE OF WEEKLY GOAL SETTING WORKSHEET....69

APPENDIX J: SAMPLE HCHF FIDELITY OBSERVATION CHECKLIST....70

APPENDIX K: PARENTAL CONSENT FORM............................74

APPENDIX L: BASELINE PARTICIPANT SURVEY ......................77

APPENDIX M: ANTHROPOMETRIC MEASUREMENT FORM.............86

APPENDIX N: HCHF PARTICIPANT EVALUATION FORM...............87

APPENDIX O: CFPQ SUBSCALES AND CORRESPONDING ITEMS........88

APPENDIX P: HCHF-BC ITEMS BY CONSTRUCT ....................... 90 


\section{LIST OF TABLES}

$\begin{array}{ll}\text { TABLE } & \text { PAGE }\end{array}$

Table 1. Baseline Characteristics of Study Participants...........................27

Table 2. Paired Samples t-test Values for Mother's Pre/Post Intervention Feeding

Practices from Subscales from the CFPQ........................................29

Table 3. Paired Samples t-test Values for Mother's Pre/Post Intervention Diet and Physical Activity Outcomes from the HCHF-BC................................. 30

Table 4. Paired Samples t-test Values for Mother's Pre/Post Intervention Parenting and Home Food Environment Outcomes from the HCHF-BC......................... 31

Table 5. Missing Pattern Analysis Comparing Continuous Demographic Variables between Study Completers and Non-Completers................................ 32

Table 6. Missing Pattern Analysis Comparing Selected Categorical Demographic

Variables between Study Completers and Non-Completers..........................33 


\section{LIST OF FIGURES}

FIGURE

PAGE

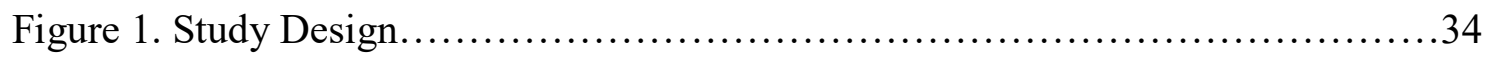

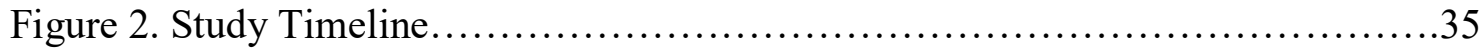




\section{CHAPTER 1}

The Impact of the Healthy Children, Healthy Families Curriculum on Maternal Food Parenting Practices

Laura Otterbach ${ }^{1}$, Geoffrey Greene ${ }^{1}$, Colleen Redding ${ }^{2}$, Alison Tovar ${ }^{1}$

${ }^{1}$ Department of Nutrition and Food Sciences, University of Rhode Island, Fogarty Hall, Kingston, RI 02881, USA

${ }^{2}$ Department of Psychology, University of Rhode Island, Chafee Hall, Kingston, RI 02881, USA 


\section{Introduction}

Prevention of childhood obesity continues to be a public health priority. ${ }^{1}$ In 2011 2012, $16.9 \%$ of children and adolescents in the United States (US) were obese. ${ }^{1}$ This is concerning, given that childhood obesity is associated with increased risk for many diseases such as heart disease, hypertension, and type 2 diabetes. ${ }^{1,2}$ In addition, obese and overweight children are more likely to be obese adults which puts them as increased risk for adverse health outcomes across the lifespan.,

Despite recent reductions in childhood obesity rates, disparities among race/ethnicity persist nationwide. ${ }^{1,5-7}$ For example, using data from $2011-2012$, over $22 \%$ of Hispanic youth aged 2-19 were obese in the US, as compared to $14.1 \%$ of nonHispanic white youth and $8.6 \%$ of non-Hispanic Asian youth. ${ }^{1}$ In the state of Rhode Island (RI) these disparities are even greater. In 2011, $25 \%$ of Hispanic kindergarteners (5 yrs) in RI were obese, as compared to $14 \%$ of non-Hispanic White and $11 \%$ of nonHispanic Black kindergarteners. ${ }^{6}$ These rates increase as children reach $7^{\text {th }}$ grade $(12 \mathrm{yrs})$, as $30 \%$ of Hispanic $7^{\text {th }}$ graders, $23 \%$ non-Hispanic black and $17 \%$ of non-Hispanic white $7^{\text {th }}$ graders were obese in $2011 .^{6}$ These rates are consistently highest in Hispanic populations, which is concerning given that this population is one of the largest ethnic minority groups not only in Rhode Island but in the US as well, and this population is expected to grow ${ }^{1,6}$. Obesity prevention programs that focus on Hispanic populations are needed to reduce these racial/ethnic disparities and to help continue to reduce national obesity rates ${ }^{1,6}$. Given these disparities and the increased risk for developing obesity later in life, ${ }^{1,3-5,8}$ involving parents to aide in childhood obesity prevention is critical. ${ }^{9-11,13-15}$ 
Parents play an important role in shaping a child's diet and eating behaviors early in life. ${ }^{9-11,13-15,18,19,22,28,30,31}$ Parents serve as an authority figure and role model for their children $^{9-11,13-15,}$, and can improve the environments by reducing obesogenic factors and increasing healthy parenting practices. ${ }^{9-11,13-15,18-20,28}$ Given that parents play a key role in shaping a child's diet and feeding habits, ${ }^{18-21}$ interventions that include parents as agents of change are often successful in facilitating behavior changes at the family level. ${ }^{9-11,13-15}$ Parents are important gate keepers for the home food environment, and play a role in obesity risk through several parenting behaviors. For example, parents use strategies to maintain or alter a child's food intake, known as food parenting practices ${ }^{18}$. Food parenting practices are goal directed behaviors that influence the amount or type of food a child eats, and include modeling, involvement, and encouragement of balance and variety. ${ }^{13,16,18,19}$ These food parenting practices have been identified as important factors in the development of weight gain and obesogenic eating behaviors in young children. $12,13,16-22,24,25,28$

Food parenting practices influence the diet quality and weight status of young children. ${ }^{12,13,16,-22,24,25,28}$ One longitudinal study among Mexican American families found that parental use of food restriction predicted higher weight status at year 1, while pressure to eat was related to a lower weight status. ${ }^{25}$ Similarly, another longitudinal study with 323 mother-child dyads (child ages 1.5-2 yrs), found that instrumental feeding, or food as reward, was positively correlated with child BMI-z score at multiple time points. ${ }^{12}$ Given these results, childhood obesity interventions should include parent education on the impact of food parenting practices and tools to promote practices that are associated with favorable health outcomes. ${ }^{9-11,13-16,19,27,28}$ 
Most of the literature on food parenting practices has focused primarily on negative food parenting practices such as pressure to eat and restriction. ${ }^{12,13,18,21,24-28} \mathrm{~A}$ recent systematic review by Shloim et al. reviewed studies investigating food parenting practices, and practices in relation to weight status in children ages 4-12 years. The review identified 22 previous studies that examined the relationship between food parenting practices and child weight status. ${ }^{28}$ Of those studies, a majority focused on negative food parenting practices, and the associations of these types of practices with child weight status. ${ }^{28}$ Most studies were focused on practices like pressure to eat, restriction, and instrumental and emotional feeding, and very few studies included positive/supportive food parenting practices in their main findings. ${ }^{28}$ The review highlights the need for future interventions to focus on parenting and positive food parenting practices ${ }^{28}$, such as modeling, child involvement, and encouragement. ${ }^{16}$ In studies focusing on these positive food parenting practices, modeling, involvement, and encouragement have also shown to be associated with diet quality and BMI. ${ }^{9-12,18,20,25}$ For example, among 699 child-parent dyads, parental encouragement/modeling and overall positive food parenting practices were associated with favorable diet quality and weight status in children aged 6-11 years. ${ }^{20}$ Children's BMI z-scores were negatively associated with parent encouragement/modeling, and positively associated with permissive food parenting practices. ${ }^{20}$ These associations suggest that along with information about modifying negative food parenting practices, it is important to target positive food parenting practices when designing interventions as a way to improve child diet habits and therefore weight status. 
Although there have been multiple interventions to prevent childhood obesity, ${ }^{28-31}$ few have targeted the modification of positive food parenting practices set within a community setting among low-income Hispanic populations. The Healthy Children, Healthy Families (HCHF) is an evidence-based curriculum for parents of 3-11-year-old children that focuses on the importance of developing healthy lifestyle behaviors through parenting style, food parenting practices, and the home environment. ${ }^{32-35} \mathrm{HCHF}$ is a family-centered obesity prevention curriculum/intervention that focuses on parenting skills, with the goal of facilitating healthy lifestyle changes within a family system. ${ }^{31-34}$ The HCHF curriculum was designed for community nutrition educators to deliver to lowincome parents throughout an 8-week series of weekly workshops. ${ }^{32-36}$

Although previous studies utilizing the HCHF curriculum have found improvements in parent and child health behaviors following the intervention, ${ }^{34,35}$ these studies have not comprehensively measured changes in food parenting practices. ${ }^{34-36}$ For example, Lent et al. found that after participating in this curriculum, 500 parents $^{35}$ reported significant improvements in both their and their child's diet and physical activity behaviors, including reduced soda and fast food intake, higher low-fat dairy, vegetable, and fruit intakes, and less TV watching and more active play for children. ${ }^{35}$ In addition, the study found improvements in self-reported parenting behaviors (eating with their child, autonomy) following the intervention. ${ }^{35}$ Given the focus of the HCHF curriculum on food parenting practices, it is important to understand the impact of the intervention on these practices. This may shed light on these practices as possible mediators of these outcomes as well as future targets for intervention improvement. 
The purpose of the present study was to assess if mothers participating in a childhood obesity intervention utilizing the HCHF curriculum would improve their selfreported positive food parenting practices pre/post intervention. In addition, the study aimed to assess changes in parent and child behaviors related to dietary intake and activity.

\section{Methods}

\section{Study Design}

The study utilized a non-experimental, within-subjects pre/post design. Parents of 3-11-year-old children participated in the evidence-based 8-week Healthy Children, Healthy Families (HCHF) curriculum/workshop series, which was taught by community paraprofessionals (navegantes) primarily in Spanish. The 8-week intervention was delivered to a total of four groups of mothers (approximately 5-15 mothers/group) between April and December 2015. The curriculum is focused on parenting techniques to improve family health behaviors including healthy eating, physical activity, and positive parenting practices.

The primary hypothesis was that parents would improve their scores on the supportive food parenting practice of modeling. The secondary hypothesis was that parents would improve their scores on supportive food parenting practices of encouragement of balance and variety and involvement. Additional exploratory hypotheses were that there would be improvements in parent and child diet and activity outcomes such as increases in intake of fruits, vegetables, and low-fat dairy, increased physical activity, and decreased consumption of energy dense snacks, fast food, and soda. 


\section{Study Setting}

The study involved a community partnership with Clínica Esperanza/Hope Clinic (CEHC), a free healthcare clinic located in the Olneyville area of Providence, RI. The clinic provides free healthcare services to the uninsured, and also provides community health programs delivered by trained paraprofessional educators. As an existing community platform for health interventions, CEHC was chosen as the community partner for this study, and was the primary setting for the delivery of the intervention. All protocols of the proposed study were approved by the University of Rhode Island Institutional Review Board.

\section{Participants and Recruitment}

Eligible participants were parents or primary caregivers of children between the ages of 3-11 years, and willing to attend the weekly workshop sessions for 8 weeks. Although recruitment included both male and female participants, only one male participated. This male participant was removed from the analytic study sample in order to assess changes in mothers only. The target population was parents living in the Providence, Rhode Island area. In addition, we intended to reach a large percentage of at risk parents, specifically low-income Hispanic parents, given the demographics of this area. The median household income in Olneyville is $\$ 17,538$, and $61 \%$ of the population is Hispanic. ${ }^{37}$

Recruitment fliers (Appendix C) including study information were placed throughout the Olneyville area and distributed to organizations including community centers, local businesses, parks, libraries, and churches. In addition, the navegantes and community partners including healthcare clinics and current health-related programs 
helped do in person recruitment in the community. Interested parents were screened inperson or via telephone to determine eligibility. Recruitment efforts continued on a rolling basis by continuously recruiting eligible parents to participate in the next available group.

\section{Intervention}

The HCHF curriculum was taught by navegantes (paraprofessional educators) employed through CEHC. Navegantes participated in a formal 2-day training on the HCHF curriculum, conducted by representatives from Cornell University. The training reviewed the foundations of the curriculum, answered frequently asked questions, addressed common barriers, and allowed for the practice of activities and lessons in the curriculum. The training also provided the navegantes with valuable background knowledge of the overall goals of the curriculum as well as tools and techniques surrounding curriculum flow, delivery, and evaluation.

The HCHF curriculum highlights 'paths to success' and 'keys to success' to facilitate healthy changes in families (Appendix D). ${ }^{32,33}$ These paths and keys to success, which serve as the backbone of the HCHF curriculum, highlight several positive food parenting practices, and encourage parents to use these practices with their families at home. Examples include setting a good example for their child (modeling), and offering

healthy choices within limits (guiding). ${ }^{32,33}$ By integrating health education with parental support and tools to promote firm and responsive parenting, HCHF is a curriculum tailored to the specific needs of parents of 3 to 11-year old children.

The HCHF curriculum addresses health education topics surrounding diet, activity, and the home environment. Topics include consuming water or milk instead of 
sugar sweetened beverages, reducing high-fat and high-sugar foods, eating more fruits and vegetables, playing actively, reducing screen time, and having family meals. ${ }^{32,33}$ The curriculum includes problem-solving strategies for health-related behavior change, and utilizes parenting scenarios and role-play to address barriers to behavior change. ${ }^{32,33}$ Specifically, the curriculum focuses on strategies that parents can use to improve their food parenting practices, including emphasizing their child's role in food preparation, encouraging their children to eat a balanced and varied diet, and modeling healthy eating behaviors to their children (Appendix E). In addition, each session also included an active play break, featuring a family-friendly activity that parents can do with their families at home (Appendix F). ${ }^{32,33}$ Every session includes a healthy recipe for parents to taste (Appendix G), and a weekly prize/incentive, such as pedometers or cooking utensils (Appendix H). For weekly goal-setting, at the end of each session parents identified a 'healthy step' or goal for the week ahead (Appendix I). ${ }^{32,33}$

To assess parent participation, attendance was recorded at each session. Study completers were considered for data analysis if they attended at least five out of the eight class sessions. To assess fidelity of the intervention, a portion of the HCHF sessions were observed. Out of the 32 sessions (8 sessions/group, 4 groups total), 19 sessions, or 59\% were observed. At least 2 sessions/group were observed. Fidelity assessment was conducted by a trained research assistant using previously developed observation checklists corresponding with each lesson/session of the HCHF intervention ${ }^{32}$ (Appendix J). Using the completed observation checklist, intervention fidelity was high (97\%), indicating that the navegantes delivered the intervention as it was intended based on the protocol of the HCHF curriculum. 


\section{Procedures}

Prior to the first session, baseline measures for each group of participants were collected. On the day of the first session, each mother-child dyad arrived at CEHC before the proposed session start time to complete baseline measures. All study materials were available in both English and Spanish. Mothers completed a consent form for themselves (Appendix K) and a written permission form their child if their child was under 7 years of age. Children who were over 7 years of age completed an assent form. Mothers then completed a baseline survey, which consisted of demographic questions, questions from the Comprehensive Feeding Practices Questionnaire (CFPQ), and the 16-item HCHF behavior checklist (Appendix L). Once mothers completed the survey, both mother and child were led to a separate area where a research assistant measured and recorded their baseline height and weight measurements (Appendix M). Once height and weight measurements of each mother-child dyad were completed, session one began. Although the focus of this intervention was for the mothers, mothers were encouraged to bring their children to the sessions where complimentary child care and/or a separate nutrition curriculum was delivered to the children. Mothers were compensated for their time with a $\$ 10$ gift card at the end of the first session. Mother-child dyads then returned to CEHC weekly for a total of eight sessions to complete the intervention. On the last week (session 8), the survey and measurement process described above was repeated to collect post-intervention data. Mothers were compensated for their time with a $\$ 40$ gift card at the end of the last session. In addition to completing a post-intervention survey, mothers also completed an evaluation survey from the HCHF curriculum which evaluated their opinions of the program (Appendix N). 


\section{Measures}

\section{Anthropometrics}

Standing height and weight measurements of each parent-child dyad were taken using standardized procedures. ${ }^{38}$ Measurements were taken in a private area to assure confidentiality of measurements and to increase the comfort of participants. Each parentchild dyad was instructed to wear light clothing and remove footwear, and if applicable, asked to take down their hair to ensure measurement accuracy. Each parent and child had measurements (height and weight) taken twice to confirm measurement precision. Height was measured using a portable stadiometer (Seca 213). Weight was measured using a calibrated digital scale (Seca 813). To assess parent BMI, the mean calculation for weight and height for each data collection point was used to calculate a BMI score (pre and post). Pre and post-intervention BMI z-scores and percentiles were calculated for children, using the means for height and weight, in addition to date of birth and sex. ${ }^{39,40}$

\section{Survey Protocol}

The survey was designed to be self-administered and consisted of 84 questions. Although it was designed to be self-administered, each participant was asked if they needed assistance completing the survey. If the participant needed assistance, a bilingual research assistant or navegante read questions aloud to ensure the participant understood each question and answer option. Parents answered each question as it pertains to their child involved in the study. If a parent has more than one child between ages $3-11$, they were instructed to answer questions about the youngest child within the 3-11 age range. The survey took participants approximately 20-30 minutes to complete. 


\section{Demographic Questionnaire}

The first section of the baseline survey consisted of 19 demographic questions. The following data was collected from mothers: age, sex, ethnicity, race, education level, number of children, ages of children, living with spouse, marital status, if they were born in the U.S., number of years in the U.S., employment status, number of jobs, health insurance status, annual household income, child date of birth, and child gender. In addition to the demographic questions, there was one question about the perceived weight status of their child, where parents are asked to circle one of seven figures/silhouettes (seven for each gender) that best represents their child, as previously described. ${ }^{41}$

\section{Comprehensive Feeding Practices Questionnaire (CFPQ)}

Self-reported food parenting practices were assessed using 29 questions from the Comprehensive Feeding Practices Questionnaire (CFPQ). ${ }^{42}$ Prior testing of the CFPQ with parents of 2-to-8-year-old children showed reasonable validity and reliability. For the purpose of this study only seven of the 12 subscales were used, including modeling ( 4 items), involvement (3 items), encouraging balance and variety (4 items), and teaching about nutrition. ${ }^{42}$ Examples for the 'encouraging balance and variety' subscale are "I encourage my child to eat a variety of foods," for the 'environment' subscale, "I keep a lot of snack food (potato chips, Doritos, cheese puffs) in my house" and for the 'involvement' subscale "I involve my child in planning family meals." ${ }^{42}$ Each question from the CFPQ has 5 answer options, ranging on a scale from disagree (1), disagree slightly (2), neutral (3), slightly agree (4), to agree (5). ${ }^{42}$ Thus, a higher score on each subscale indicates a higher frequency of the corresponding practice. One item indicates lower frequency of the feeding practice, and this item was reverse coded prior to scoring. Subscale means 
were calculated for seven subscales, and changes in subscale means pre/post will be assessed. The CFPQ subscales and corresponding items for the primary and secondary outcomes of this study are listed in Appendix O.

Each item on the CFPQ is loaded onto a specific subscale, and Cronbach's alphas were calculated from the baseline CFPQ outcomes for our primary and secondary outcomes (modeling, involvement, encouragement of balance and variety). The results for Cronbach's alphas were as follows: modeling $($ alpha $=0.878)$, involvement $($ alpha $=$ 0.927), and encouragement of balance and variety (alpha $=0.629)$.

\section{Healthy Children, Healthy Families Behavior Checklist (HCHF-BC)}

Measures of self-reported parent and child diet, physical activity, and screen time behaviors were assessed using the previously used HCHF behavior checklist. ${ }^{35,36}$ The 16item behavior checklist assessed frequency of parent and child health behaviors, including diet habits (11 items) and physical activity/screen time behaviors ( 3 items). ${ }^{35,36}$ For example, "How often do your children play actively for at least 60 minutes a day?" and "How many days a week do you usually eat vegetables?"35,36 Each item was assessed using a 5-point scale with answers ranging on frequency specific to each question, starting with the least frequent answer option to the most frequent. For example, for the question "How often do your children play actively for at least 60 minutes a day?" the answer options range from (1) once in a while, (2) 1-2 days each week, (3) 3-4 days each week, (4) 5-6 days each week, to (5) every day. Items were scored 1-5 with a higher total score indicating higher frequency of the corresponding behavior. The HCHF-BC items organized by construct are listed in Appendix P. 


\section{Statistical Analysis}

Statistical analysis was performed using SPSS version 23. Descriptive statistics for study variables were calculated including means and standard deviations for continuous variables and frequencies and percentages for categorical variables. ShapiroWilk test was used to analyze normality of the data. Forty percent $(n=16)$ of participating mothers were lost to follow-up and did not complete the full intervention or postintervention measures. To address the missing data due to participants lost to follow up, a multiple imputation analysis for missing data was run to impute missing data values for study outcomes. A missing value analysis with all outcome variables, in addition to all demographic variables that may provide information on the trends of missing values was created. This included all post-intervention outcomes from the HCHF-BC and the CFPQ, in addition to demographic variables (age, number of children). Multiple imputation analysis was used to impute missing data values from participants lost to follow up for post-intervention outcomes from the HCHF-BC and CFPQ, using demographic variables (listed above), and pre-survey items from the HCHF-BC and CFPQ included as predictors in the model. Based on previous literature, 140 imputations were used ${ }^{43-45}$. Pooled values from the data set with imputed values were used for analysis of primary and secondary outcomes, with values of study completers and pooled values displayed in Tables 2-4. Corrections for multiple comparisons was not executed given that the variables of interest were correlated. Paired samples t-tests were performed to assess for statistically significant changes pre/post intervention. Cronbach's alphas were calculated for the CFPQ subscales, modeling, encouragement of balance and variety and involvement. Significance level was set at $\mathrm{p}<0.05$. 


\section{Results}

\section{Study Sample}

A total of 41 participants were recruited and completed baseline measurements. Of those, twenty-five participants completed the intervention and post-intervention measures. One male participant who completed the intervention was removed for data analysis to assess changes in mothers only. After multiple imputation (described above) for missing follow up data for 16 participants, the final sample for data analysis was 40 mothers.

Baseline descriptive statistics on the characteristics of the study sample are reported in Table 1 for the study sample $(n=40)$, study completers $(n=24)$, and study noncompleters $(n=16)$. Overall, mothers were approximately $38.3 \pm 11.3$ years of age, and 98\% were Hispanic/Latino. Almost half of the mothers had less than a high school degree, and a majority of the mothers were not born in the United States. The sample was primarily low-income, with a majority of the mothers reporting an annual household income of $\$ 15,000$ or less. Over three quarters of the mothers were either overweight or obese $(81 \%)$. For the children, over half were either overweight or obese $(57 \%)$, and the mean BMI z-scores was $1.2 \pm 1.5$.

There were several differences in demographic variables between study completers and non-completers. For example, greater than $50 \%$ of non-completers had less than a high school education, as compared to only one-third of completers. There were also differences in employment status between study completers and noncompleters, with $46.7 \%$ of non-completers employed full time, as compared to $16.7 \%$ of completers. 


\section{Primary \& Secondary Outcomes}

Pre/post intervention outcomes from the Comprehensive Feeding Practices Questionnaire (CFPQ) are summarized in Table 2. From individual subscales on the CFPQ, there was a significant increase in mother's use of modeling $(\mathrm{p}<0.01)$. There was an increase in the use of encouragement of balance and variety, however this was not a significant change $(\mathrm{p}>0.05)$. There was a significant increase in maternal use of involvement $(\mathrm{p}<0.05)$.

\section{Exploratory Outcomes}

For outcomes related to other food parenting practices, there were several nonsignificant changes $(\mathrm{p}>0.05)$. These non-significant changes include an increase in teaching about nutrition, a decrease in the use of food as a reward, and increases in both restriction for health and restriction for weight control.

Results on pre/post outcomes from the self-reported 16-item HCHF-BC are displayed in Table 3 (Parent and Child Diet \& Activity) and Table 4 (Parenting \& Home Environment). For diet and activity behaviors of mothers, mothers significantly increased their frequency of both fruit and vegetable intake. Mothers also increased their reported intake of low-fat dairy products, however this was not a significant increase $(\mathrm{p}>0.05)$. There was a significant decrease in soda consumption for mothers $(\mathrm{p}<0.05)$. Mothers increased their frequency of physical activity, however this was not a significant increase $(\mathrm{p}>0.05)$.

For children, there were no significant changes in fruit or vegetable intake $(p>0.05)$. There was a significant increase in child consumption of low-fat dairy products $(\mathrm{p}<0.01)$. There were non-significant changes in child soda consumption or child screen 
time $(\mathrm{p}>0.05)$. There was a significant increase in frequency of physical activity for children $(\mathrm{p}<0.05)$.

The remaining five items of the HCHF-BC related to parenting practices and the home food environment. There was a significant increase in parental use of autonomy $(\mathrm{p}<0.05)$, defined as parents letting their child decide how much food to eat during mealtime. For food availability, there were non-significant decreases in energy dense snack availability, and fast/convenience food availability ( $\mathrm{p}>0.05)$. There was also an increase in fruit availability, but this was not significant $(\mathrm{p}>0.05)$. Unexpectedly, there was a significant decrease in the frequency of family meals $(\mathrm{p}<0.001)$.

The mean attendance rate for all mothers who completed baseline data measures $(n=40)$ was $4.6 \pm 2.6$ sessions. Of all mothers that completed the 8-week intervention and completed post-intervention measures $(n=24), 100 \%$ attended at least 5 out of the 8 sessions and were considered 'study completers'. Of the study completers, the mean attendance rate was $6.5 \pm 1.2$ sessions. Overall, the participant dropout rate was $40 \%$, with $60 \%$ of the original sample consisting of study completers.

Out of the 24 mothers who completed the intervention, $96 \%$ completed a postintervention evaluation survey, designed to assess participant opinions on the program. Results from the evaluation survey indicate overall positive attitudes of the program. Of those who completed the survey, 100\% agreed that they "enjoyed coming to the HCHF sessions," "learned a lot of new things during the program," "what they learned was useful for them and their families," and that they "learned new parenting skills that helped them get along better with their children." Ninety-five percent of mothers agreed 
that the time of the sessions was convenient for them, and $88 \%$ agreed the location was convenient.

\section{Discussion}

This study assessed changes in mothers' use of positive food parenting practices and diet and activity habits of parents and children pre/post participation in the evidenced-based HCHF intervention. Post intervention there were increases in the frequency of supportive food parenting practices, including modeling healthy eating behaviors, encouraging a balanced and varied diet in their child, and involving their child in food decisions. In addition, mothers also reported significant improvements in their fruit and vegetable and soda intake and their child's low-fat dairy intake and physical activity. Mothers also reported significant improvements in the use of autonomy, or allowing their child to decide how much to eat during meals. Based on these results, this intervention may aide in the prevention of obesity through improvements in food parenting practices and certain health behaviors among a low-income Hispanic population.

Similar to other studies, this study found that food parenting practices are modifiable, and are effective targets for behavior change to improve family health ${ }^{25,26}$ One longitudinal study examined several food parenting practices 6, 12, and 24 months post participation in a parent-centered childhood obesity treatment program. ${ }^{26}$ The study found that parental restriction, pressure to eat, and monitoring significantly decreased at 24 months post intervention, indicating that improvements in these food parenting practices can be sustained in the long term. ${ }^{26}$ This study however was a longer treatment intervention compared to the study reported in this paper and also focused on more of the 
"negative" food parenting practices; it is possible that parents may be more amenable to changing more positive feeding practices within a shorter period of time. ${ }^{43}$ These improvements in food parenting practices support development of healthy eating, favorable diet quality and weight outcomes over time. ${ }^{16-21,24-26}$ Similar to the findings in this paper, another study found that the children of parents participating in an intervention which focused on improving role modeling of healthy behaviors, significantly increased their fruit and vegetable consumption, and parents also significantly influenced a decrease in children's fast/convenience food consumption, which was not observed in the control group ${ }^{43}$ However, the intervention was delivered over the course of one school year, whereas the intervention in the current study was eight weeks. While our study did not find significant changes in child intake of fruit and vegetables, we found nonsignificant increases in these areas. The results of this intervention suggest that parent modeling of healthy eating behaviors, or acting as a role model, is a feasible target for behavior change in childhood obesity prevention efforts, and long term interventions to promote these behaviors may be more effective.

The improvements seen in mother and child diet and activity behaviors are similar to previous studies utilizing the $\mathrm{HCHF}$ intervention, ${ }^{34,35}$ whereby significant improvements in parent and child diet behaviors, including significant increases for fruit, vegetable, and low-fat dairy intake, and significant reductions in parent soda intake were found..$^{35}$ These findings make sense in light of the topics covered during the curriculum where the importance of fruit and vegetable intake, drinking water or milk instead of sweetened beverages are thoroughly covered. ${ }^{32,33,35}$ Although the population type and size slightly varied, we found very similar results which adds to the possible efficacy of 
this intervention in improving health behavior outcomes for parents and children. Despite in the current study having a smaller sample size, there were significant outcomes similar to these findings.

The current study has some limitations. Sample size was relatively small in this study, as participant recruitment, enrollment, and retention was a challenge. However, researchers attempted to reduce barriers to study participation by providing child care, healthy meals, and in some cases transportation to the intervention. In addition, the use of multiple imputation allowed for missing data for participants who dropped out of the intervention to be imputed using a state of the art approach, which was utilized to support the analysis of study completers. ${ }^{43-45}$ Although the study did not utilize an experimental design, it utilized an evidence-based curriculum in a community-based setting, and was able to reach an at-risk population. ${ }^{1-8} \mathrm{By}$ targeting a population that was primarily Hispanic and low-income, the intervention was able to reach parents of children who are disproportionately at risk for obesity. ${ }^{1,5-7}$

However, successful implementation of this intervention was resource intensive, requiring joint efforts from researchers, educators, and community partners. Participant recruitment and retention remains a challenge, specifically in research studies and community programs that aim to reach parents. ${ }^{46-48}$ Common barriers to parent participation include transport, parents' work schedules and competing demands on family time. ${ }^{47-49}$ Limiting barriers to participation in research studies and community programs may help to enroll and retain more participants. ${ }^{48,49}$ Ultimately, the success of the program as evidenced by the health outcomes suggest parent participation in the $\mathrm{HCHF}$ intervention is a feasible approach to improve behaviors linked to obesity risk. 


\section{Conclusions \& Implications}

The current study found that after participation in the HCHF intervention, mothers significantly increased their use of positive food parenting practices, which are associated with favorable weight status and diet habits in children. ${ }^{9-12,18,20,25}$ Future research should test the efficacy of this intervention utilizing an experimental design and explore food parenting practices as a mediator to weight gain. Although there are several obesity prevention studies, few have specifically targeted or measured food parenting practices and few have taken a family-based approach. ${ }^{14,15,30,31,34,35}$ Interventions to prevent childhood obesity may include some information on modifying food parenting practices, but few have had a comprehensive focus and/or have not measured changes in these practices pre/post intervention. ${ }^{26,27,34-36}$

Future interventions should include information on how to improve food parenting practices, ${ }^{11-13,16,18}$ and should adequately measure these changes pre/post intervention, ${ }^{16,23}$ given the influence of food parenting practices on a child's diet and

weight status. ${ }^{9,12,13,16-21,24-28}$ Based on the results of the current study, future interventions, including those using the HCHF curriculum, should take into account the important influence of food parenting practices in an effort to facilitate healthy family changes and improve the diet quality and weight status of parents and children, and subsequently reduce the risk of childhood obesity. 


\section{References:}

1. Ogden CL, Carroll MD, Kit BK, Flegal KM. Prevalence of childhood and adult obesity in the United States, 2011-2012. J Am Med Assoc. 2014;311:806-814.

2. U.S. Department of Agriculture. Let's Move: Learn the Facts. http://www.letsmove.gov/learn-facts/epidemic-childhood-obesity. Accessed April 10, 2015.

3. Biro FM, Wien M. Childhood obesity and adult morbidities. Am J Clin Nutr. 2010;91:1499S - 1505S.

4. Reilly J, Kelly J. Long-term impact of overweight and obesity in childhood and adolescence on morbidity and premature mortality in adulthood: systematic review. Int J Obes. 2011;35:891-898.

5. Centers for Disease Control and Prevention (CDC), Division of Nutrition, Physical Activity, and Obesity. National Center for Chronic Disease Prevention and Health Promotion. Childhood Obesity Facts. http://www.cdc.gov/obesity/data/childhood.html. Accessed February 4, 2015.

6. The Burden of Overweight and Obesity in Rhode Island, 2011. Rhode Island Department of Health. Initiative for a Healthy Weight Program. 2011.

7. Lovasi GS, Hutson MA, Guerra M, Neckerman KM. Built environments and obesity in disadvantaged populations. Epidemiol Rev. 2009;31:7-20.

8. Centers for Disease Control and Prevention (CDC), Division of Nutrition, Physical Activity, and Obesity. National Center for Chronic Disease Prevention and Health Promotion. Childhood Obesity Causes \& Consequences. http://www.cdc.gov/obesity/childhood/causes.html. Accessed February 1, 2015.

9. Golan M, Crow S. Parents are key players in the prevention and treatment of weightrelated problems. Nutrition Reviews. 2004;62:39-50.

10. Golan M, Weizman A. Familial approach to the treatment of childhood obesity. $J$ Nutr. 2001;33:102-107.

11. Golan M. Parents as agents of change in childhood obesity - from research to practice. Int J Pediatr Obes. 2006;1:66-76.

12. Rodgers RF, Paxton SJ, Massey R, et al. Maternal feeding practices predict weight gain and obesogenic eating behaviors in young children: a prospective study. Int $J$ Behav Nutr Phy. 2013;10:1-10. 
13. Patrick H, Hennessy E, McSpadden K, Oh A. Parenting styles and practices in children's obesogenic behaviors: Scientific gaps and future research directions. Childhood Obes. 2013;9:S73-86.

14. Davison KK, Jurkowski JM, Lawson HA. Reframing family-centred obesity prevention using the Family Ecological Model. Public Health Nutr. 2013;16(10):1861-1869.

15. Davison KK, Lawson HA, Coatsworth JD. The family-centred action model of intervention layout and implementation (FAMILI): The example of childhood obesity. Health Promotion Practice. 2010;13:454-461.

16. Vaughn AE, Ward DS, Fisher JO, Faith MS, Hughes SO, Kremers S, MusherEizenman DR, O'Connor TM, Patrick H, Power TG. Fundamental constructs in food parenting practices: a content map to guide future research. Nutrition Reviews. 2016;0:1-20.

17. Sonneville KR, Rifas-Shiman SL, Kleinman KP, Gortmaker SL, Gillman MW, Taveras EM. Associations of obesogenic behaviors in mothers and obese children participating in a randomized trial. Obesity. 2012;20:1449-1454.

18. Sleddens E, Kremers S, Stafleu A, Dagnelie PC, De Vries NK, Thijs C. Food parenting practices and child dietary behaviors. Prospective relations and the moderating role of general parenting. Appetite. 2014;79:42-50.

19. Vollmer RL, Mobley AR. Parenting styles, feeding styles, and their influence on child obesogenic behaviors and body weight. A review. Appetite. 2013;71:232-241.

20. Couch SC, Glanz K, Zhou C, Sallis JF, Saelens BE. Home Food Environment in Relation to Children's Diet Quality and Weight Status. J Acad Nutr Diet. 2014;114(10):1569-1579.

21. Farrow CV, Haycraft E, Blissett JM. Teaching our children when to eat: how parental feeding practices inform the development of emotional eating - a longitudinal experimental design. Am J Clin Nutr. 2015;101:908-913.

22. Pinard CA, Yaroch AL, Hart MH, et al. Measures of the home environment related to childhood obesity: a systematic review. Public Health Nutr. 2012;15:97-109.

23. Vaughn AE, Tabak RG, Bryant MJ, et al. Measuring parent food practices: a systematic review of existing measures and examination of instruments. Int J Behav Nutr Phys Act. 2013;10:1-27.

24. Spruijt-Metz D, Li CY, Cohen E, Birch L, Goran M. Longitudinal influence of mother's child-feeding practices on adiposity in children. J Pediatr-Us. 2006;148:314-320. 
25. Tschann JM, Martinez SM, Penilla C, Gregorich SE, Pasch LA, de Groat CL, Flores E, Deardorff J, Greenspan LC, Butte NF. Parental feeding practices and child weight status in Mexican American families: a longitudinal analysis. Int J Behav Nutr Phys Act. 2015;12:66.

26. Burrows T, Warren JM, Collins CE. The impact of a child obesity treatment intervention on parent child-feeding practices. Int J Pediatr Obes. 2010;5:43-50.

27. Holland JC, Kolko RP, Stein RI, Welch RR, Perri MG, Schectman KB, Saelens BE, Epstein LH, Wilfley DE. Modifications in parent feeding practices and child diet during family-based behavioral treatment improve child zBMI. Obesity. 2014;22:E119-E126.

28. Shloim N, Edelson LR, Martin N, Hetherington MM. Parenting styles, feeding styles, feeding practices, and weight status in 4-12 year-old children: A systematic review of the literature. Front Psychol. 2015;6:1849.

29. Dawson-McClure S, Brotman LM, Theise R, Palamar JJ, Kamboukos D, Barajas RG, Calzada EJ. Early childhood obesity prevention in low-income, urban communities. $J$ Prev Interv Community. 2014;42:152-166.

30. Birch LL, Ventura AK. Preventing childhood obesity: what works? Int J Obesity. 2009;33:S74-S81.

31. Olson S. Obesity in the early childhood years: State of the science and implementation of promising solutions: Workshop in brief. Institute of Medicine. 2016.

32. University C. Parent Workshops Healthy Children, Healthy Families: Parents Making a Difference! Food and Nutrition Education in Communities 2013; https://www.fnec.cornell.edu/Our_Initiatives/CHANCE_HCHF.cfm. Accessed 05/10/15.

33. Dickin KL, Hill TF, Dollahite JS. The Collaboration for Health, Activity, and Nutrition in Children's Environments (CHANCE): A Program Integrating Parenting and Nutrition Behavioral Education Improves Food, Active Play, and Parenting Practices in Low-income Families. Faseb J. 2010;24.

34. Dickin KL, Hill TF, Dollahite JS. Practice-Based Evidence of Effectiveness in an Integrated Nutrition and Parenting Education Intervention for Low-Income Parents. $J$ Acad Nutr Diet. 2014;114(6):945-950.

35. Lent M, Hill TF, Dollahite JS, Wolfe WS, Dickin KL. Healthy children, healthy families: parents making a difference! A curriculum integrating key nutrition, 
physical activity, and parenting practices to help prevent childhood obesity. $J$ Nutr Educ Behav. 2012;44(1):90-92.

36. Dickin KL, Lent M, Lu AH, Sequeira J, Dollahite JS. Developing a Measure of Behavior Change in a Program to Help Low-Income Parents Prevent Unhealthful Weight Gain in Children. J Nutr Educ Behav. 2012;44(1):12-21.

37. Olneyille: Action for a healthier community. Providence, Rhode Island: Rhode Island Department of Health; 2011.

38. Lohman TG. Advances in Body Composition Assessment. Current Issues in Exercise Science Series, Monograph No. 3. Champaign, IL: Human Kinetics Publishers, 1992:200-201.

39. Must A, Anderson SE. Body mass index in children and adolescents: considerations for population-based applicants. Int J Obes. 2006;30:590-594.

40. The Children's Hospital of Philadelphia. Pediatric Z-Score Calculator. http://stokes.chop.edu/web/zscore/. Accessed April 7, 2014.

41. Killion L, Hughes SO, Wendt JC, Pease D, Nicklas TA. Minority mothers' perceptions of children's body size. Int J Pediatr Obes. 2006;1:96-102.

42. Musher-Eizenman D, Holub S. Comprehensive feeding practices questionnaire: Validation of a new measure of parental feeding practices. J Pediatr Psychol. 2007;32:960-972.

43. Natale RA, Messiah SE, Asfour L, Uhlhorn SB, Delamater A, Arheart KL. Role modeling as an early childhood obesity prevention strategy: Effect of parents and teachers on preschool children's healthy lifestyle habits. J Dev Behav Pediatr. 2014;35:378-387.

44. Graham JW. Missing Data Analysis: Making it work in the real world. Annu Rev of Psychol. 2009;60:549-576.

45. Baraldi AN, Enders CK. An introduction to modern missing data analyses. Journal of School Psychology. 2010;48:5-37.

46. Schafer JL, Graham JW. Missing Data: Our view of the state of the art. Psychol Methods. 2002;7:147-177.

47. Baker CN, Arnold DH, Meagher S. Enrollment and attendance in a parent training prevention program for conduct problems. Prev Sci. 2010;12:126-138.

48. Axford N, Lehtonen M, Kaoukji D, Tobin K, Berry V. Engaging parents in parenting programs: Lessons from research and practice. Child Youth Serv Rev. 2012;34:20612071. 
49. Lucas PJ, Curtis-Tyler K, Arai L, Stapley S, Fagg J, Roberts H. What works in practice: user and provider perspectives on the acceptability, affordability, implementation, and impact of a family-based intervention for child overweight and obesity delivered at scale. BMC Public Health. 2014;14:1-12. 
TABLE 1: Baseline Characteristics of Mothers ( $\mathrm{N}=40)$

\begin{tabular}{|c|c|c|c|}
\hline \multirow[t]{2}{*}{ Participant Characteristics } & $\frac{\stackrel{\text { All }}{\text { Participants }}}{\underline{(n=40)}}$ & $\frac{\begin{array}{c}\text { Study } \\
\text { Completers }\end{array}}{\underline{(n=24)}}$ & $\frac{\begin{array}{c}\text { Non- } \\
\text { Completers }\end{array}}{\underline{(\mathrm{n}=16)}}$ \\
\hline & $\underline{\mathbf{n}(\%)}$ & $\underline{\mathbf{n}(\%)}$ & $\underline{\mathbf{n}(\%)}$ \\
\hline \multicolumn{4}{|l|}{ Sex } \\
\hline Female & $40(100)$ & $24(100)$ & $16(100)$ \\
\hline Age (mean \pm SD) & $38.3 \pm 11.3$ & $44.1 \pm 10.8$ & $30.3 \pm 5.7$ \\
\hline \multicolumn{4}{|l|}{ Hispanic/Latino } \\
\hline Yes & $39(97.5)$ & $24(100)$ & $15(93.8)$ \\
\hline No & $1(2.5)$ & $0(0)$ & $1(6.3)$ \\
\hline \multicolumn{4}{|l|}{ Race } \\
\hline White & $17(42.5)$ & $11(45.8)$ & $6(37.5)$ \\
\hline More than one race & $7(17.5)$ & $3(12.5)$ & $4(25)$ \\
\hline Wish not to answer/don't know & $6(15)$ & $3(12.5)$ & $3(18.8)$ \\
\hline African-American & $1(2.5)$ & $0(0)$ & $1(6.3)$ \\
\hline American Indian/Alaskan Native & $1(2.5)$ & $0(0)$ & $1(6.3)$ \\
\hline Did not answer/Missing & $8(20)$ & $7(29.2)$ & $1(6.3)$ \\
\hline \multicolumn{4}{|l|}{ Education } \\
\hline Less than high school & $16(40)$ & $7(29.2)$ & $9(56.3)$ \\
\hline High school graduate/GED & $9(22.5)$ & $6(25)$ & $3(18.8)$ \\
\hline Post HS Trade/Technical school & $3(7.5)$ & $3(12.5)$ & $0(0)$ \\
\hline Some college or higher & $12(30)$ & $8(33.4)$ & $4(25)$ \\
\hline \multicolumn{4}{|l|}{ Living with Spouse } \\
\hline Yes & $22(55)$ & $15(62.5)$ & $7(43.8)$ \\
\hline No & $18(45)$ & $9(37.5)$ & $9(56.3)$ \\
\hline \multicolumn{4}{|l|}{ Marital Status } \\
\hline Never Married & $12(30.8)$ & $4(17.4)$ & $8(50)$ \\
\hline Married & $17(43.6)$ & $12(52.2)$ & $5(31.3)$ \\
\hline Divorced or Separated & $9(23.1)$ & $6(26.1)$ & $3(18.8)$ \\
\hline Widowed & $1(2.6)$ & $1(4.3)$ & $0(0)$ \\
\hline \multicolumn{4}{|l|}{ Born in the U.S. } \\
\hline No & $33(84.6)$ & $22(91.7)$ & $11(73.3)$ \\
\hline Yes & $6(15.4)$ & $2(8.3)$ & $4(26.7)$ \\
\hline \multicolumn{4}{|l|}{ Country of Origin } \\
\hline Guatemala & $11(33.3)$ & $7(33.3)$ & $4(25)$ \\
\hline Dominican Republic & $9(27.3)$ & $5(23.8)$ & $4(25)$ \\
\hline Other & $13(39.4)$ & $9(42.9)$ & $8(50)$ \\
\hline Years in the U.S. (mean \pm SD) & $11.7 \pm 7.6$ & $12.2 \pm 7.5$ & $10.4 \pm 8.0$ \\
\hline \multicolumn{4}{|l|}{ Employment Status } \\
\hline Employed Full time ( $>35 \mathrm{hrs} / \mathrm{wk}$ ) & $11(28.2)$ & $4(16.7)$ & $7(46.7)$ \\
\hline Employed Part time ( $<35 \mathrm{hrs} / \mathrm{wk})$ & $6(15.4)$ & $5(20.9)$ & $1(6.7)$ \\
\hline Unemployed/Looking for work & $12(30.8)$ & $8(33.3)$ & $4(26.7)$ \\
\hline Homemaker & $9(23.1)$ & $7(29.2)$ & $2(13.3)$ \\
\hline Student & $1(2.6)$ & $0(0)$ & $1(6.7)$ \\
\hline
\end{tabular}




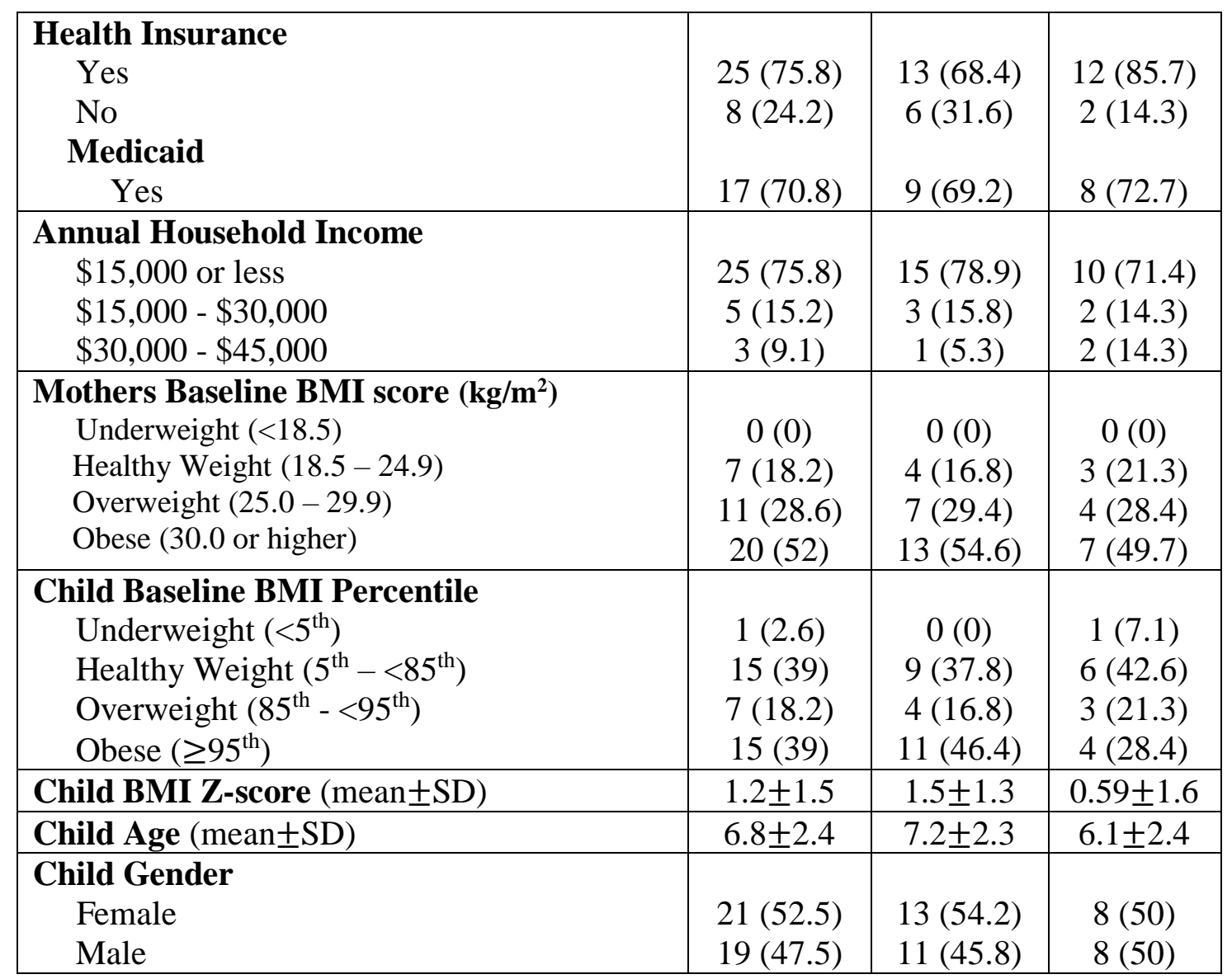


Table 2: Paired Samples t-test Values for Mother's Pre/Post Intervention Feeding Practices from Subscales from the CFPQ

\begin{tabular}{|c|c|c|c|c|c|}
\hline \multirow[b]{2}{*}{ Subscale on CFPQ } & \multirow[b]{2}{*}{$\underline{\text { Pre/Post }}$} & \multicolumn{2}{|c|}{$\begin{array}{c}\text { Study Completers } \\
(\mathrm{n}=24)\end{array}$} & \multicolumn{2}{|c|}{$\begin{array}{c}\text { Pooled Data } \\
(n=40)\end{array}$} \\
\hline & & Mean & p-value & Mean & p-value \\
\hline \multirow{2}{*}{ Modeling } & Pre & 4.65 & \multirow{2}{*}{$0.049 *$} & 4.48 & \multirow{2}{*}{$0.003 * *$} \\
\hline & Post & 4.90 & & 4.83 & \\
\hline \multirow{2}{*}{$\begin{array}{l}\text { Encouragement of } \\
\text { Balance and Variety }\end{array}$} & Pre & 4.55 & \multirow{2}{*}{$0.005^{*}$} & 4.60 & \multirow{2}{*}{0.165} \\
\hline & Post & 4.88 & & 4.77 & \\
\hline \multirow{2}{*}{ Involvement } & Pre & 4.03 & \multirow{2}{*}{$0.035^{*}$} & 3.97 & \multirow{2}{*}{$0.018 *$} \\
\hline & Post & 4.60 & & 4.53 & \\
\hline \multirow{2}{*}{$\begin{array}{l}\text { Teaching About } \\
\text { Nutrition }\end{array}$} & Pre & 4.23 & \multirow{2}{*}{0.157} & 4.25 & \multirow{2}{*}{0.157} \\
\hline & Post & 4.50 & & 4.50 & \\
\hline \multirow{2}{*}{ Food As Reward } & Pre & 3.33 & \multirow{2}{*}{0.297} & 3.21 & \multirow{2}{*}{0.326} \\
\hline & Post & 3.03 & & 2.98 & \\
\hline \multirow{2}{*}{ Restriction for Health } & Pre & 3.88 & \multirow{2}{*}{0.129} & 3.94 & \multirow{2}{*}{0.271} \\
\hline & Post & 4.19 & & 4.14 & \\
\hline \multirow{2}{*}{$\begin{array}{l}\text { Restriction for } \\
\text { Weight Control }\end{array}$} & Pre & 3.18 & \multirow{2}{*}{0.072} & 3.13 & \multirow{2}{*}{0.107} \\
\hline & Post & 3.54 & & 3.41 & \\
\hline
\end{tabular}

Significant changes labeled $* \mathrm{p}<0.05, * * \mathrm{p}<0.01, * * * \mathrm{p}<0.001$.

Items were assessed using the Comprehensive Feeding Practices Questionnaire (CFPQ) using a 1-5 Likert scale ranging from 'Disagree' to 'Agree.' 
Table 3: Paired Samples t-test Values for Mother's Pre/Post Intervention Diet and Physical Activity Outcomes from the HCHF-BC

\begin{tabular}{|c|c|c|c|c|c|}
\hline \multirow[b]{2}{*}{$\frac{\text { Item on }}{\text { HCHF-BC }}$} & \multirow[b]{2}{*}{$\underline{\text { Pre/Post }}$} & \multicolumn{2}{|c|}{$\begin{array}{c}\text { Study Completers } \\
(n=24)\end{array}$} & \multicolumn{2}{|c|}{$\begin{array}{l}\text { Pooled Data } \\
\qquad(n=40)\end{array}$} \\
\hline & & $\underline{\text { Mean }}$ & p-value & $\underline{\text { Mean }}$ & p-value \\
\hline \multirow{2}{*}{$\begin{array}{l}\text { Parent Fruit } \\
\text { Intake }\end{array}$} & Pre & 3.04 & \multirow{2}{*}{$0.003 * *$} & 3.08 & \multirow{2}{*}{$0.003 * *$} \\
\hline & Post & 3.83 & & 3.80 & \\
\hline \multirow{2}{*}{$\begin{array}{c}\text { Parent } \\
\text { Vegetable } \\
\text { Intake }\end{array}$} & Pre & 2.88 & \multirow{2}{*}{$0.003 * *$} & 2.77 & \multirow{2}{*}{$0.000 * * *$} \\
\hline & Post & 3.58 & & 3.57 & \\
\hline \multirow{2}{*}{$\begin{array}{c}\text { Parent LF } \\
\text { Dairy Intake }\end{array}$} & Pre & 2.92 & \multirow{2}{*}{0.067} & 2.88 & \multirow{2}{*}{0.054} \\
\hline & Post & 3.33 & & 3.34 & \\
\hline \multirow{2}{*}{$\begin{array}{l}\text { Parent Soda } \\
\text { Intake }\end{array}$} & Pre & 1.54 & \multirow{2}{*}{0.233} & 1.87 & \multirow{2}{*}{$0.037 *$} \\
\hline & Post & 1.33 & & 1.42 & \\
\hline \multirow{2}{*}{$\begin{array}{c}\text { Parent } \\
\text { Physical } \\
\text { Activity }\end{array}$} & Pre & 2.21 & \multirow{2}{*}{$0.025 *$} & 2.35 & \multirow{2}{*}{0.064} \\
\hline & Post & 2.83 & & 2.84 & \\
\hline \multirow{2}{*}{$\begin{array}{l}\text { Child Fruit } \\
\text { Intake }\end{array}$} & Pre & 4.08 & \multirow{2}{*}{0.063} & 4.18 & \multirow{2}{*}{0.834} \\
\hline & Post & 4.17 & & 4.13 & \\
\hline \multirow{2}{*}{$\begin{array}{c}\text { Child } \\
\text { Vegetable } \\
\text { Intake }\end{array}$} & Pre & 2.75 & \multirow{2}{*}{0.188} & 2.77 & \multirow{2}{*}{0.185} \\
\hline & Post & 3.08 & & 3.08 & \\
\hline \multirow{2}{*}{$\begin{array}{c}\text { Child LF } \\
\text { Dairy Intake }\end{array}$} & Pre & 3.16 & \multirow{2}{*}{$0.004^{* *}$} & 3.16 & \multirow{2}{*}{$0.003 * *$} \\
\hline & Post & 3.96 & & 3.94 & \\
\hline \multirow{2}{*}{$\begin{array}{l}\text { Child Soda } \\
\text { Intake }\end{array}$} & Pre & 1.54 & \multirow{2}{*}{0.814} & 1.55 & \multirow{2}{*}{0.558} \\
\hline & Post & 1.58 & & 1.66 & \\
\hline \multirow{2}{*}{$\begin{array}{c}\text { Child Physical } \\
\text { Activity }\end{array}$} & Pre & 3.00 & \multirow{2}{*}{$0.029 *$} & 3.11 & \multirow{2}{*}{$0.035^{*}$} \\
\hline & Post & 3.67 & & 3.66 & \\
\hline Child Screen & Pre & 2.13 & & 2.18 & \\
\hline Time & Post & 1.96 & 0.293 & 1.97 & 0.199 \\
\hline
\end{tabular}

Significant changes labeled $* \mathrm{p}<0.05, * * \mathrm{p}<0.01, * * * \mathrm{p}<0.001$. 
Table 4: Paired Samples t-test Values for Mother's Pre/Post Intervention Parenting and Home Food Environment Outcomes from the HCHF-BC

\begin{tabular}{|c|c|c|c|c|c|}
\hline \multirow{2}{*}{$\underline{\underline{\text { Item on }}} \underline{\text { HCHF-BC }}$} & \multirow[b]{2}{*}{$\underline{\text { Pre/Post }}$} & \multicolumn{2}{|c|}{$\begin{array}{c}\text { Study Completers } \\
(\mathrm{n}=\mathbf{2 4})\end{array}$} & \multicolumn{2}{|c|}{ Pooled Data $(n=40)$} \\
\hline & & $\underline{\text { Mean }}$ & p-value & $\underline{\text { Mean }}$ & p-value \\
\hline \multirow{2}{*}{$\begin{array}{c}\text { Parent } \\
\text { Autonomy }\end{array}$} & Pre & 2.88 & \multirow{2}{*}{0.062} & 2.92 & \multirow{2}{*}{$0.036^{*}$} \\
\hline & Post & 3.63 & & 3.59 & \\
\hline \multirow{2}{*}{$\begin{array}{l}\text { Family } \\
\text { Meals }\end{array}$} & Pre & 4.04 & \multirow{2}{*}{$0.011^{*}$} & 4.18 & \multirow{2}{*}{$0.000^{* * *}$} \\
\hline & Post & 3.29 & & 3.29 & \\
\hline \multirow{2}{*}{$\begin{array}{c}\text { Energy } \\
\text { Dense } \\
\text { Snacks } \\
\text { Availability } \\
\end{array}$} & Pre & 2.08 & \multirow[b]{2}{*}{0.307} & 2.15 & \multirow[b]{2}{*}{0.183} \\
\hline & Post & 1.79 & & 1.85 & \\
\hline \multirow{2}{*}{$\begin{array}{l}\text { Fast Food } \\
\text { Availability }\end{array}$} & Pre & 1.46 & \multirow{2}{*}{0.213} & 1.53 & \multirow{2}{*}{0.075} \\
\hline & Post & 1.29 & & 1.32 & \\
\hline \multirow{2}{*}{$\begin{array}{c}\text { Fruit } \\
\text { Availability }\end{array}$} & Pre & 4.38 & \multirow{2}{*}{0.170} & 4.18 & \multirow{2}{*}{0.937} \\
\hline & Post & 4.58 & & 4.51 & \\
\hline
\end{tabular}

Significant changes labeled $* \mathrm{p}<0.05, * * \mathrm{p}<0.01, * * * \mathrm{p}<0.001$. 
Table 5: Missing Pattern Analysis Comparing Selected Continuous Variables between Study Completers $(n=24)$ and Non-Completers $(\mathbf{n}=16)$

\begin{tabular}{|c|c|c|}
\hline Variable & $\begin{array}{c}\text { Mean } \\
\text { Completer }\end{array}$ & $\begin{array}{c}\text { Mean } \\
\text { Non-Completer }\end{array}$ \\
\hline $\begin{array}{c}\text { Age in years } \\
\text { (Mother)* }\end{array}$ & 44.1 & 30.3 \\
\hline $\begin{array}{c}\text { Number of } \\
\text { Children }\end{array}$ & 1.4 & 1.8 \\
\hline Years in the U.S. & 12.2 & 10.4 \\
\hline $\begin{array}{c}\text { Maternal BMI } \\
\left(\mathbf{m} / \mathbf{k g}^{\mathbf{2}}\right)\end{array}$ & 30.9 & 29.9 \\
\hline
\end{tabular}

* Significant difference between completer and non-completer $(\mathrm{p}<0.05)$ 
Table 6: Missing Pattern Analysis Comparing Selected Categorical Variables between Study Completers $(n=24)$ and Non-Completers $(\mathbf{n}=16)$

\begin{tabular}{|c|c|c|c|}
\hline \multicolumn{2}{|c|}{$\underline{\text { Variable }}$} & \% of Completers & $\frac{\% \text { of }}{\text { Non-Completers }}$ \\
\hline \multirow{2}{*}{ Education } & $\begin{array}{l}\text { Less than High } \\
\text { School }\end{array}$ & $45 \%$ & $55 \%$ \\
\hline & $\begin{array}{c}\text { High School or } \\
\text { More }\end{array}$ & $84 \%$ & $16 \%$ \\
\hline \multirow{2}{*}{$\begin{array}{l}\text { Marital } \\
\text { Status }\end{array}$} & Never Married & $33 \%$ & $67 \%$ \\
\hline & Married & $71 \%$ & $29 \%$ \\
\hline \multirow{2}{*}{$\begin{array}{c}\text { Employment } \\
\text { Status }\end{array}$} & Full Time & $36 \%$ & $64 \%$ \\
\hline & Part Time & $80 \%$ & $20 \%$ \\
\hline \multirow{2}{*}{$\begin{array}{c}\text { Annual } \\
\text { Household } \\
\text { Income }\end{array}$} & $\$ 30,000$ or less & $60 \%$ & $40 \%$ \\
\hline & $\begin{array}{l}\$ 30,000- \\
\$ 45,000\end{array}$ & $33 \%$ & $67 \%$ \\
\hline
\end{tabular}




\section{Figure 1: Study Design}

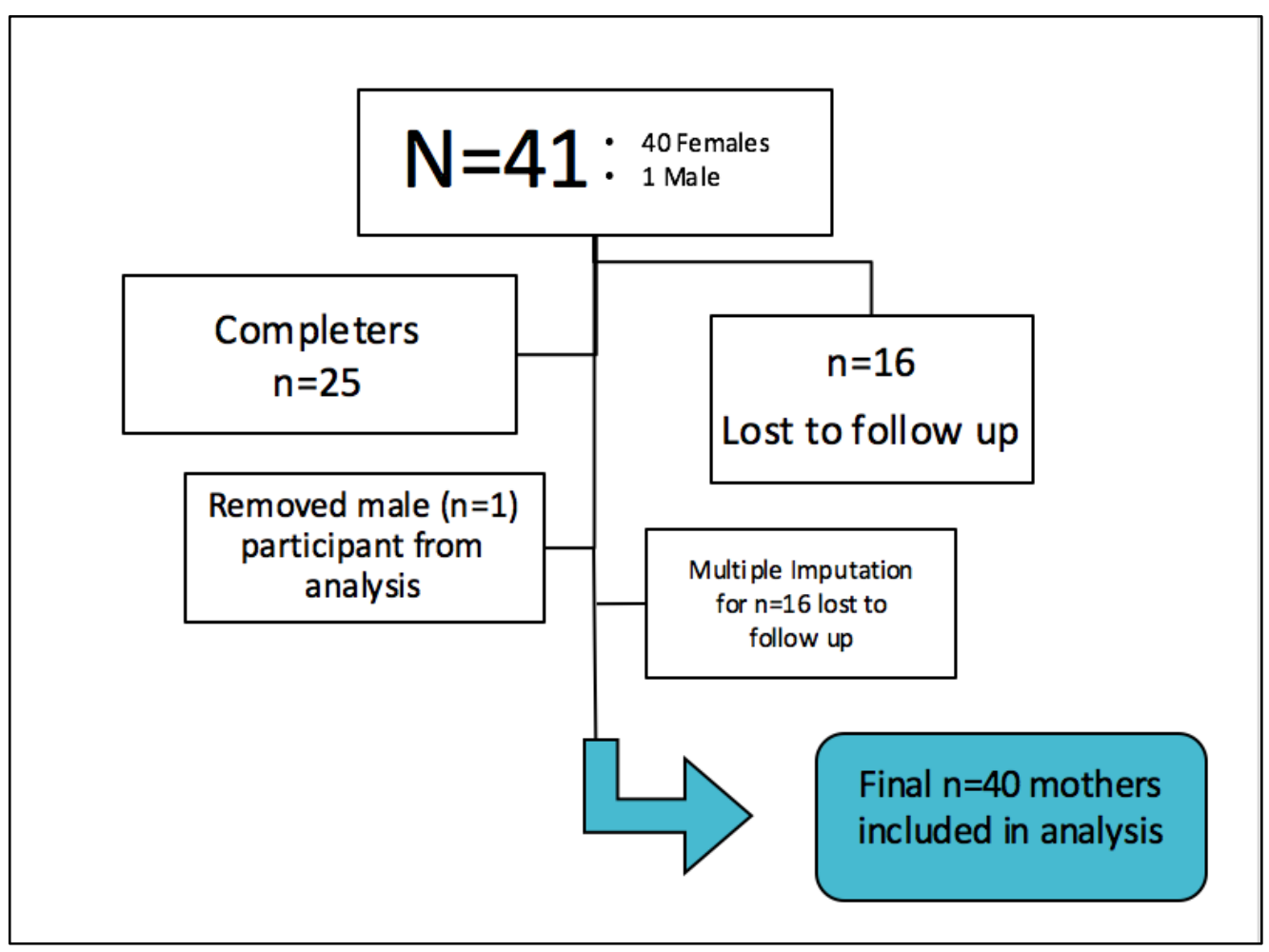


Figure 2: Study Timeline

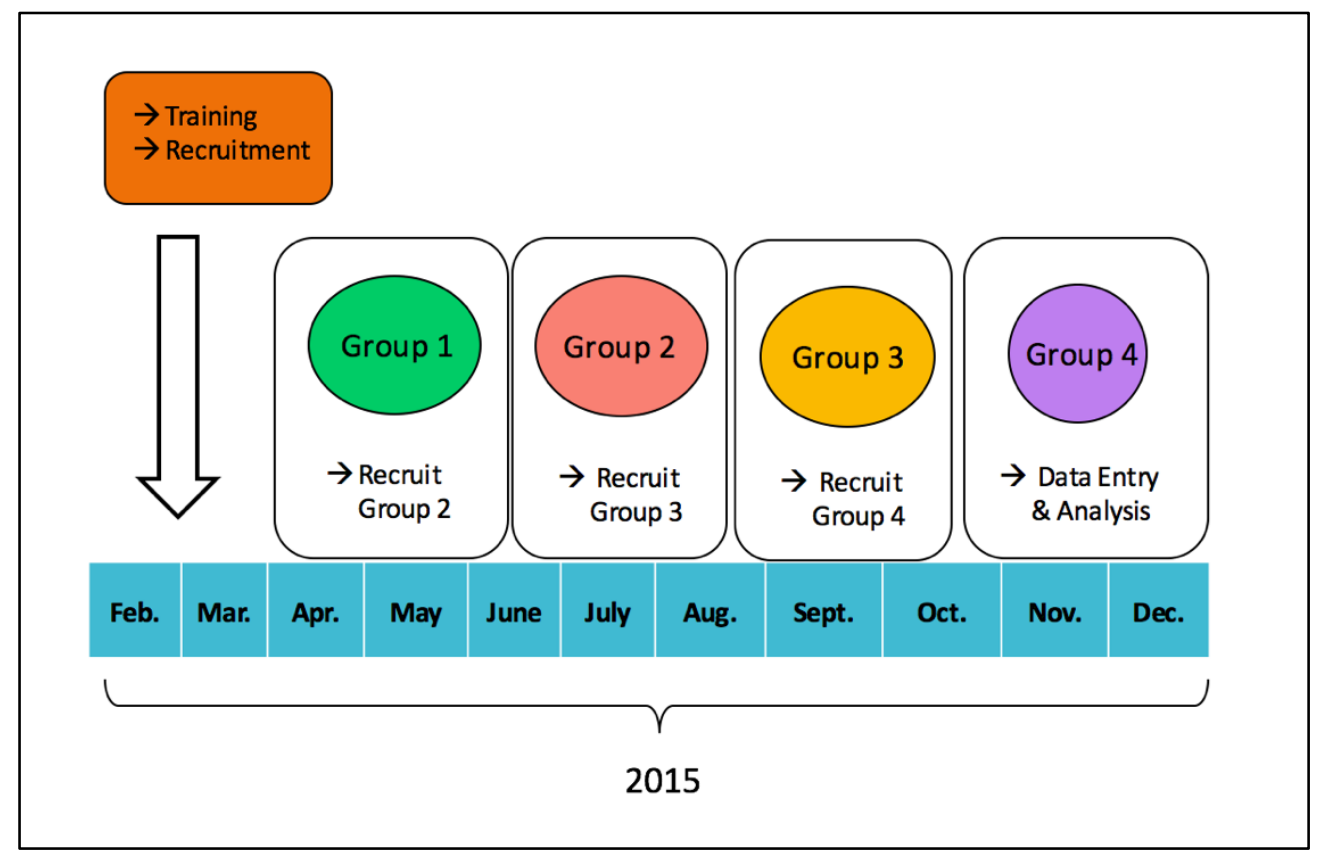




\section{APPENDIX A}

\section{EXTENDED LITERATURE REVIEW}

\section{Prevalence of Childhood Obesity and Its Consequences}

Childhood obesity is a significant public health issue in the United States (US), as childhood obesity rates have tripled over the past three decades. ${ }^{1,2}$ In the US, nearly one in every three children in the U.S. overweight or obese. ${ }^{1,2}$ These rates are concerning, as obese children are more likely to be obese adults, and often develop chronic health problems associated with obesity, including type 2 diabetes, heart disease, asthma, and

hypertension. ${ }^{1,2}$ As a result, reducing the prevalence of childhood obesity is considered an important public health initiative. ${ }^{2,3}$ Recent data collected from the 2011-2012 National Health and Nutrition Examination Survey (NHANES) demonstrated that overall, childhood obesity prevalence has decreased since $2003 .{ }^{1}$ For example, the obesity prevalence for children ages $2-5$ decreased from $13.9 \%$ in 2003 , to $8.4 \%$ in $2012 .{ }^{1}$ Increased recognition of childhood obesity as an important public health issue, and efforts of prevention programs nationwide likely contribute to these declining rates. However, rates of childhood obesity remain high, and further research and interventions are important to combat this public health issue. Therefore, the development of evidencebased childhood obesity interventions, and the continued evaluation of these interventions are critical to continue these efforts. 


\section{Childhood Obesity Disparities Among At-Risk Populations}

\section{Hispanic Populations}

Despite recent reductions in childhood obesity rates, disparities among race/ethnicity persist nationwide. ${ }^{1}$ For example, using data from $2011-2012$, over $22 \%$ of Hispanic youth aged 2-19 were obese in the U.S., as compared to $14.1 \%$ of non-Hispanic white youth and $8.6 \%$ of non-Hispanic Asian youth. ${ }^{1}$ In the state of Rhode Island these disparities are even greater. In 2011, $25 \%$ of Hispanic kindergarteners (5 yrs) in RI were obese, as compared to $14 \%$ of non-Hispanic White and $11 \%$ of non-Hispanic Black kindergarteners. ${ }^{4}$ These rates increase as children reach $7^{\text {th }}$ grade $(12 \mathrm{yrs})$, as $30 \%$ of Hispanic $7^{\text {th }}$ graders, $23 \%$ non-Hispanic black and $17 \%$ of non-Hispanic white $7^{\text {th }}$ graders were obese in $2011^{4}$. These rates are consistently highest in Hispanic populations, which is concerning given that this population is one of the largest ethnic minority groups not only in Rhode Island but in the U.S. as well, and this population is expected to grow. ${ }^{1,4}$ Obesity prevention programs that focus on Hispanic populations are needed to reduce these racial/ethnic disparities and to help continue to reduce national obesity rates.

\section{Low-Income Populations}

Childhood obesity prevalence is also disproportionally higher in low-income populations. ${ }^{1,5-8}$ For example, obesity prevalence in children ages $2-4$ are highest in families living at or below the federal poverty level. ${ }^{5}$ Built environments surrounding low-income areas likely contribute to "obesogenic" characteristics that may increase risk factors of obesity. ${ }^{6}$ The built environment surrounding low-income neighborhoods often lack access to safe areas and facilities for physical activity and play, and often have a greater amount of fast-food/convenience food outlets and less access to supermarkets. ${ }^{6}$ 
Targeting behavioral and environmental factors that contribute to increased obesity prevalence in low-income populations is an important target for future prevention strategies. $^{6,9}$

\section{Influences of the Development of Obesogenic Behaviors}

The specific causes of the development of obesity are complex, with many environmental and psychosocial factors influencing the onset of obesity. A review of evidence for the treatment of overweight and obesity in children highlights the important factors to consider in effective interventions. The review suggests that research supports the use of multicomponent lifestyle interventions as an effective approach for obesity treatment (i.e. interventions that include a dietary and physical activity modification component, behavioral strategies, and parental/familial involvement, to take into account the environmental factors contributing to obesity risk. ${ }^{10}$ Interventions must take into account the "obesogenicity" of an environment, as previously defined by Swinburn et al. as the sum of influences the surroundings, opportunities, or conditions of life have on promoting obesity in individuals or populations." ${ }^{11}$ Environmental factors that may contribute to obesogenicity include parents, homes, neighborhoods, schools, communities, and government systems. ${ }^{11,12}$ Although there are multiple interacting factors that contribute to obesogenicity, this review will focus on parental factors and factors within the home environment, including diet quality, food availability, home food environment, physical activity and screen time behaviors, and maternal food parenting practices. 


\section{Diet Quality}

Diet quality is an important factor contributing to childhood obesity risk. Evidence shows that positive eating patterns, and high diet quality is associated with favorable health outcomes. ${ }^{13}$ These healthy dietary patterns include those highlighted in the 2015-2020 Dietary Guidelines for Americans, which promote the consumption of fruits, vegetables, whole grain, legumes, nuts/seeds, lean proteins, seafood, and low-fat dairy products. ${ }^{13}$ These dietary components contribute to decreased risk for multiple diseases including diabetes, heart disease, cancer, and hypertension. ${ }^{13}$ However, the diet quality of Americans of all ages is not reflective of these dietary guidelines. Moreover, in children between the ages of 4 and 13, average daily consumption of vegetables was between 0.8 and 1.1 cups, while the recommended amount is between 1.5-3.0 cups/day. ${ }^{13}$ Additionally, children are consuming added calories from added sugars and energy-dense snacks. ${ }^{13}$ For example, for children ages 4 to 13 , daily percentage of kcals contributed by added sugars range from $15-17 \%$, while the recommended limit is $10 \%$ or less. ${ }^{13}$ For children, this is particularly concerning as proper nutrition during childhood is imperative for development of healthy weight status and diet habits into adulthood. ${ }^{13}$ The home environment is a target for improving diet quality, ${ }^{14}$ as two thirds of the foods children consume is from home. ${ }^{15}$

\section{Home Food Environment}

Parents and family members play an important role in a variety of factors contributing to childhood obesity by acting as the gate-keepers of the home food environment. ${ }^{16-18}$ The home food environment model described by Rosenkranz \& Dzewaltowski is defined as overlapping interactive domains composed of built and 
natural, sociocultural, political and economic, micro-level and macro-level environments, and depicts the contextual environment where a child develops eating behaviors. ${ }^{14}$ In addition to providing food in the home, or the physical environment, parents are also responsible for providing a positive sociocultural environment. ${ }^{19}$

A cross-sectional study conducted by Couch et al. explored the home food environments relation to child diet quality and weight status, using DASH score and BMI z score, respectively. ${ }^{20}$ The study defined the home food environment as including the physical environment (e.g. food availability), and the sociocultural environment (e.g. parenting behaviors and feeding practices). ${ }^{20}$ The study found that the home food environment explained $28 \%$ of the variance in child BMI and $9-21 \%$ of the variance in various measures of child dietary quality. ${ }^{20}$ Several aspects of the sociocultural environment are based around food parenting practices, such as parental modeling/encouragement, indicating that these parenting behaviors are possible areas to target in childhood obesity prevention.

\section{Physical Activity \& Screen Time}

Another component of the home environment that contributes to childhood obesity risk is the physical activity (PA) and screen time behaviors of families. One study consisting of 421 parent-child dyads (child ages 5-10 yrs) and examined the relationships between parenting styles and practices and child physical activity and screen time. ${ }^{21}$ Child PA was assessed using accelerometers and parent questionnaires, and child screen time was assessed using surveys and screen time logs. ${ }^{21}$ Parenting styles and practices were assessed via questionnaires (Langer), and child BMI percentile was calculated. ${ }^{21}$ There was an inverse association between BMI and physical activity, with each unit 
increase in BMI, activity decreased by 8 minutes per day. ${ }^{21}$ Parental support for PA, which was observed across parenting styles, was positively associated with child PA. ${ }^{21}$ Regression models found associations of child BMI and parenting styles in relation to screen time. ${ }^{21}$ Child BMI was positively related to screen time, with each unit increase in BMI was associated with a $20-23 \%$ increase in the likelihood that the child had more than 2 hours of screen time per day. ${ }^{21}$ Parenting styles and practices were also associated with screen time. Both authoritarian and permissive parenting styles were associated with a $133 \%$ and $113 \%$ respective increase in the likelihood of a child having more than 2 hours of daily screen time. ${ }^{21}$ Parenting styles and practices are predictors of screen time and PA behaviors, in addition to food parenting practices, suggesting the importance of parenting style as a target of behavior change in childhood obesity prevention efforts.

\section{Parenting Styles}

Parenting style is defined by a set of attributes, attitudes, and ways of interacting with children that can influence child outcomes. ${ }^{22}$ Four general types of parenting have been identified..$^{22-24}$ These parenting styles are categorized based on parental levels of demandingness/firmness and responsiveness. Authoritative parenting is characterized by high levels of both firmness and responsiveness, while the authoritarian style is categorized by high levels of firmness, and low levels of responsiveness. ${ }^{22,24}$ In indulgent parenting style, parents are high in responsiveness but low in firmness, while neglectful parenting style is categorized by low levels of firmness and responsiveness. ${ }^{18,22,24}$ Longitudinal studies have found associations between parenting style and child BMI. Specifically, the authoritative parenting style has been found to be protective against 
child overweight over time. ${ }^{19,24-26}$ These general parenting styles can be applied to the style in which parents approach child feeding, known as parent feeding styles. ${ }^{18,24,27}$ Similar to general parenting style, parent feeding styles have been linked to both positive and negative outcomes related to obesity. For example, in a cross-sectional study of 231 primary caregivers, authoritative feeding was positively associated with the availability of fruits and vegetables. ${ }^{28}$ Authoritative feeding was also positively associated with child consumption of dairy and vegetables, while authoritarian feeding was negatively associated with availability of fruit and vegetables, and child consumption of vegetables. ${ }^{28}$ Given the connection between parenting style, feeding style, and obesity risk, interventions should address parenting behaviors and feeding styles as a target of behavior change to improve outcomes related to obesity.

Research studies involving parenting behaviors and styles may help to clarify the relationships between parenting and behaviors linked to childhood obesity. One study by Hubbs-Tait et al. aimed to identify the relationship between parental feeding styles and practices and general parenting styles, in order to understand how to target parenting practices to increase intervention efficacy. ${ }^{27}$ For instance, parental use of responsibility, restricting, monitoring, and modeling all significantly predicted authoritative parenting style in a sample of 239 parents. ${ }^{27}$ Additionally, restricting, pressuring, and monitoring all significantly predicted authoritarian parenting style. ${ }^{27}$ The researchers concluded that general parenting styles are associated with parental feeding practices, and that interventions/programs should include approaches to behavior change that take into account parenting styles and family dynamics. ${ }^{27}$ 


\section{Food Parenting Practices}

Parental feeding practices, more recently defined as food parenting practices, have been identified as important factors in the development of weight gain and obesogenic eating behaviors in young children. ${ }^{29-32}$ Food parenting practices are defined as goal directed behaviors that influence the amount or type of food a child eats ${ }^{29-32}$. Examples of food parenting practices include modeling, restriction, involvement, and encouragement. ${ }^{29-32}$ These food parenting practices, have been identified as important factors in the development of weight gain and obesogenic eating behaviors in young children. ${ }^{29,32-38}$

Food parenting practices influence the diet quality and weight status of young children..$^{29,32-38}$ One longitudinal study among Mexican American families found that parental use of food restriction predicted higher weight status at year 1, while pressure to eat was related to a lower weight status. ${ }^{36}$ Similarly, another longitudinal study with 323 mother-child dyads (child ages 1.5-2 yrs), found that instrumental feeding, or food as reward, was positively correlated with child BMI z score at multiple time points. ${ }^{29}$ Given these results, it makes sense for childhood obesity interventions to include parent education on the impact of food parenting practices and tools to promote positive practices. ${ }^{15,16,18,32,33,38-42}$

Most of the literature on food parenting practices has focused primarily on negative food parenting practices such as pressure to eat and restriction. ${ }^{29-31,33,35,36,38,42,43}$ A recent systematic review by Shloim et al. reviewed studies investigating parenting styles and practices, and feeding practices in relation to weight status in children ages 412 years. The review identified 22 previous studies that examined the relationship 
between food parenting practices and child weight status. ${ }^{38}$ Of those studies, a majority focused on negative food parenting practices, and the associations of these types of practices with child weight status. ${ }^{38}$ Most studies were focused on practices like pressure to eat, restriction, and instrumental and emotional feeding, and very few studies included positive/supportive food parenting practices in their main findings. ${ }^{38}$ Therefore, the review discusses the need for future interventions to focus on authoritative parenting and positive food parenting practices ${ }^{38}$, such as autonomy support or promotion and structure, which include modeling, child involvement, and encouragement. ${ }^{32}$

In studies focusing on these positive/supportive food parenting practices, encouragement, modeling, and involvement have also shown to be associated with diet quality and BMI. ${ }^{20,29,31,36,39-41}$ For example, among 699 child-parent dyads, parental encouragement/modeling and overall authoritative food parenting practices were associated with favorable diet quality and weight status in children aged 6-11 years. ${ }^{20}$ Children's BMI z-scores were negatively associated with parent encouragement/modeling, and positively associated with permissive food parenting practices. ${ }^{20}$ These associations suggest that along with information about modifying negative food parenting practices, it is also of importance for interventions to target positive or supportive food parenting practices as a way to improve child diet quality and therefore weight status.

In a sample of 394 parent-child dyads (children ages 18 mo. -5 yrs), parental food involvement - an authoritative feeding practice- was strongly correlated with consumption of fruits and vegetables. ${ }^{44}$ In another study of 316 mother-child dyads (child ages 2-5 yrs), maternal feeding practices were assessed using the Comprehensive Feeding 
Practices Questionnaire (CFPQ), and child dietary intake was assessed by parent completion of an eating habits questionnaire. ${ }^{45}$ In this study, supportive feeding practices, including modeling, building a healthy home food environment, involvement, encouraging balance and variety, and teaching about nutrition, were all significantly correlated with fruit and vegetable intake. ${ }^{45}$ These positive feeding practices are potential targets for interventions as behaviors parents can use to decrease development of obesogenic behaviors.

\section{Family-Centered Interventions}

Given the important influence of parent feeding practices on childhood obesity risk, it is important for interventions to be family-centered. Interventions that are tailored to the needs of the family and include as many members of the family are more successful than individual-focused interventions. ${ }^{16,17,40,41}$ Parents serve as an authority figure and role model for their children, and can improve the environments by reducing obesogenic factors and increasing healthy family practices. ${ }^{39}$ An article by Golan \& Crow published in Nutrition Reviews discussed the role of parents in childhood obesity preventions, and emphasized that since parents provide the food environment for their children, parents should be considered key players and agents of change in the prevention and treatment of childhood obesity. ${ }^{39}$

\section{Culturally Tailored Interventions}

Another characteristic of successful family-based interventions are that they are culturally tailored. A randomized controlled trial by Barkin et al. explored the effectiveness of a family-centered, culturally tailored intervention on BMI in LatinoAmerican families. ${ }^{46}$ Seventy-five parent-child dyads participated in the study (children 
ages 2-6). ${ }^{46}$ The intervention group participated in Salud con Familia (Health with the Family) program, which consisted of 12 weekly skill-building sessions at a community recreation center. ${ }^{46}$ The program was designed to improve family nutrition, while increasing physical activity and reducing sedentary behaviors of the family, and took into account several cultural factors of the study sample. ${ }^{46} \mathrm{BMI}$ of the parents and children were assessed and the children who participated in the intervention experienced an average reduction in BMI of 0.51 over a period of 3 months. ${ }^{46}$ The results of this study indicate that community-engaged, culturally-tailored interventions can successfully change children's early growth patterns such as BMI, and may be an effective approach for childhood obesity interventions. Information that is useful for parents involves skillbuilding techniques surrounding parenting practices, which equip parents with the tools they need to facilitate behavior changes in their family. By providing more useful and applicable information, parents will be more likely to benefit from interventions tailored to their learning needs.

\section{HCHF Curriculum}

One intervention that emphasizes the importance of positive feeding practices, and allows for community-based tailoring is the evidence-based Healthy Children, Healthy Families (HCHF) intervention. The HCHF intervention is an evidence-based curriculum for parents of 3-11-year-old children that focuses on the importance of developing healthy lifestyle behaviors through parenting style, food parenting practices, and the home environment. ${ }^{47-50} \mathrm{HCHF}$ is a family-centered obesity prevention curriculum/intervention that focuses on parenting skills, with the goal of facilitating healthy lifestyle changes within a family system. ${ }^{47-50}$ The HCHF curriculum was 
designed for community nutrition educators to deliver to low-income parents throughout an 8-week series of weekly workshops. ${ }^{47-49}$ By focusing on family lifestyles and parenting, HCHF is a curriculum tailored to participants by meeting the needs of lowincome parents with young children. ${ }^{47-49}$

The HCHF curriculum was designed for use in the Expanded Food Nutrition Education Program (EFNEP) by Cornell University through the Collaboration for Health, Activity, and Nutrition in Children's Environments (CHANCE) ${ }^{47-50}$ Upon development of the HCHF curriculum, interventions began throughout New York to evaluate the success of the program. ${ }^{47-50}$ By 2012, over 500 low-income parents and caregivers of children 3-11 years of age completed the HCHF curriculum. Participating parents reported significant improvements in their child's diet and physical activity behaviors in addition to improvements in self-reported parenting behaviors. ${ }^{47-50}$ Although the program has collected self-reported measures on diet and physical activity, researchers have not collected comprehensive data on outcomes related to specific feeding practices. ${ }^{50,51}$ The validated behavior checklist tool used to measure pre/post intervention behavior changes includes only two items assessing parenting practices; one question assessing family meals, and another assessing how often parents allow their child to decide how much to eat, two different parameters related to feeding. ${ }^{50,51}$ In addition to the validated behavior checklist, using validated tools such as the Comprehensive Feeding Practices Questionnaire (CFPQ) to assess changes in parent feeding practices pre/post intervention will allow researchers to determine how the HCHF curriculum influences changes in specific feeding practices. 


\section{References - Extended Literature Review}

1. Ogden CL, Carroll MD, Kit BK, Flegal KM. Prevalence of childhood and adult obesity in the United States, 2011-2012. J Am Med Assoc. 2014;311:806-814.

2. U.S. Department of Agriculture. Let's Move: Learn the Facts. http://www.letsmove.gov/learn-facts/epidemic-childhood-obesity. Accessed April $10,2015$.

3. Services USDoHaH. Healthy People 2020: Nutrition and Weight Status Objectives. 2014; http://www.healthypeople.gov/2020/topicsobjectives/topic/nutrition-and-weight-status. Accessed 4/21/15.

4. The Burden of Overweight and Obesity in Rhode Island, 2011. Rhode Island Department of Health. Initiative for a Healthy Weight Program. 2011.

5. Centers for Disease Control and Prevention (CDC), Division of Nutrition, Physical Activity, and Obesity. National Center for Chronic Disease Prevention and Health Promotion. Childhood Obesity Facts.

http://www.cdc.gov/obesity/data/childhood.html. Accessed February 4, 2015.

6. Lovasi GS, Hutson MA, Guerra M, Neckerman KM. Built environments and obesity in disadvantaged populations. Epidemiol Rev. 2009;31:7-20.

7. Dawson-McClure S, Brotman LM, Theise R, Palamar JJ, Kamboukos D, Barajas RG, Calzada EJ. Early childhood obesity prevention in low-income, urban communities. J Prev Interv Community. 2014;42:152-166.

8. Birch LL, Ventura AK. Preventing childhood obesity: what works? Int J Obesity. 2009;33:S74-S81.

9. Sallis JF, Saelens BE, Frank LD, Conway TL, Slymen DJ, Cain KL, Chapman JE, Kerr J. Neighborhood built environment and income: Examining multiple health outcomes. Soc Sci Med. 2009;68:1285-1293.

10. Altman M, Wilfley DE. Evidence Update on the treatment of overweight and obesity in children and adolescents. J Clin Child Adolesc. 2015;44:521-537.

11. Swinburn B, Egger G, Raza F. Dissecting obesogenic environments: The development and application of a framework for identifying and prioritizing environmental interventions for obesity. Prev Med. 1999;29:563-570.

12. Swinburn B, Egger G. Preventive strategies against weight gain and obesity. Obes Rev. 2002;3:289-301. 
13. U.S. Department of Health and Human Services and U.S. Department of Agriculture. 2015 - 2020 Dietary Guidelines for Americans. $8^{\text {th }}$ Edition. December 2015. Available at http://health.gov/dietaryguidelines/2015/guidelines/.

14. Rosenkranz RR, Dzewaltowski DA. Model of the home food environment pertaining to childhood obesity. Nutr Rev. 2008;66:123-140.

15. Adair LS, Popkin BM. Are child eating patterns being transformed globally? Obes Res. 2005;13:1281-1299.

16. Davison KK, Jurkowski JM, Lawson HA. Reframing family-centred obesity prevention using the Family Ecological Model. Public Health Nutr. 2013;16(10):1861-1869.

17. Davison KK, Lawson HA, Coatsworth JD. The family-centred action model of intervention layout and implementation (FAMILI): The example of childhood obesity. Health Promotion Practice. 2010;13:454-461.

18. Vollmer RL, Mobley AR. Parenting styles, feeding styles, and their influence on child obesogenic behaviors and body weight. A review. Appetite. 2013;71:232241.

19. Satter, EM. The Satter Feeding Dynamics Model. Ellyn Satter Institute. 2015. Accessed 01/15/2016. Available at: http://ellynsatterinstitute.org/other/fdsatter.php.

20. Couch SC, Glanz K, Zhou C, Sallis JF, Saelens BE. Home Food Environment in Relation to Children's Diet Quality and Weight Status. J Acad Nutr Diet. 2014;114(10):1569-1579.

21. Langer SL, Crain AL, Senso MM, Levy RL, Sherwood NE. Predicting child physical activity and screen time: Parental support for physical activity and general parenting styles. J Pediatr Psychol.2014;39:633-642.

22. Darling N, Steinberg L. Parenting style as context: An integrative model. Psychol Bull. 1993;113:487-496.

23. Maccoby, EE, Martin JA. Socialization in the context of the family: Parent-child interaction. In P.H. Mussen (Series Ed.) \& E.M. Heherington (Vol Ed.), Handbook of child psychology 1983;4 pp.1-101. New York. Wiley.

24. Stang J, Loth KA. Parenting style and child feeding practices: Potential mitigating factors in the etiology of childhood obesity. J Am Diet Assoc. 2011;111:13011305 .

25. Berge JM. A review of familial correlates of child and adolescent obesity: What has the $21^{\text {st }}$ Century taught us so far? Int J Adolesc Med Health. 2009;21:457-483. 
26. Berge JM, Wall M, Loth K, Neumark-Sztainer D. Parenting style as a predictor of adolescent weight and weight-related beahviors. $J$ Adolescent Health. 2010;46:331-338.

27. Hubbs-Tait L, Kennedy TS, Page MC, Topham GL, Harrist AW. Parental feeding practices predict authoritative, authoritarian, and permissing parenting styles. $J$ Am Diet Assoc. 2008;108:1154-1161.

28. Patrick H, Nicklas TA, Hughes SO, Morales M. The benefits of authoritative feeding style: caregiver feeding styles and children's food consumption patterns. Appetite. 2005;44:243-249.

29. Rodgers RF, Paxton SJ, Massey R, et al. Maternal feeding practices predict weight gain and obesogenic eating behaviors in young children: a prospective study. Int J Behav Nutr Phy. 2013;10:1-10.

30. Spruijt-Metz D, Li CY, Cohen E, Birch L, Goran M. Longitudinal influence of mother's child-feeding practices on adiposity in children. J Pediatr-Us. 2006;148:314-320.

31. Sleddens E, Kremers S, Stafleu A, Dagnelie PC, De Vries NK, Thijs C. Food parenting practices and child dietary behaviors. Prospective relations and the moderating role of general parenting. Appetite. 2014;79:42-50.

32. Vaughn AE, Ward DS, Fisher JO, Faith MS, Hughes SO, Kremers S, MusherEizenman DR, O'Connor TM, Patrick H, Power TG. Fundamental constructs in food parenting practices: a content map to guide future research. Nutrition Reviews. 2016;0:1-20.

33. Patrick H, Hennessy E, McSpadden K, Oh A. Parenting styles and practices in children's obesogenic behaviors: Scientific gaps and future research directions. Childhood Obes. 2013;9:S73-86.

34. Sonneville KR, Rifas-Shiman SL, Kleinman KP, Gortmaker SL, Gillman MW, Taveras EM. Associations of obesogenic behaviors in mothers and obese children participating in a randomized trial. Obesity. 2012;20:1449-1454.

35. Farrow CV, Haycraft E, Blissett JM. Teaching our children when to eat: how parental feeding practices inform the development of emotional eating - a longitudinal experimental design. Am J Clin Nutr. 2015;101:908-913.

36. Tschann JM, Martinez SM, Penilla C, Gregorich SE, Pasch LA, de Groat CL, Flores E, Deardorff J, Greenspan LC, Butte NF. Parental feeding practices and child weight status in Mexican American families: a longitudinal analysis. Int $J$ Behav Nutr Phys Act. 2015;12:66. 
37. Pinard CA, Yaroch AL, Hart MH, et al. Measures of the home environment related to childhood obesity: a systematic review. Public Health Nutr. 2012;15:97-109.

38. Shloim N, Edelson LR, Martin N, Hetherington MM. Parenting styles, feeding styles, feeding practices, and weight status in 4-12 year-old children: A systematic review of the literature. Front Psychol. 2015;6:1849.

39. Golan M, Crow S. Parents are key players in the prevention and treatment of weight-related problems. Nutrition Reviews. 2004;62:39-50.

40. Golan M, Weizman A. Familial approach to the treatment of childhood obesity. $J$ Nutr. 2001;33:102-107.

41. Golan M. Parents as agents of change in childhood obesity - from research to practice. Int J Pediatr Obes. 2006;1:66-76.

42. Holland JC, Kolko RP, Stein RI, Welch RR, Perri MG, Schectman KB, Saelens BE, Epstein LH, Wilfley DE. Modifications in parent feeding practices and child diet during family-based behavioral treatment improve child zBMI. Obesity. 2014;22:E119-E126.

43. Burrows T, Warren JM, Collins CE. The impact of a child obesity treatment intervention on parent child-feeding practices. Int J Pediatr Obes. 2010;5:43-50.

44. Ohly H, Pealing J, Hayter AKM, Pettinger C, Pikhart H, Watt RG, Rees G. Parental food involvement predicts parent and child intakes of fruits and vegetables. Appetite. 2013;69:8-14.

45. Shim JE, Kim J, Lee Y, The STRONG Kids Team. Fruit and vegetable intakes of preschool children are associated with feeding practices facilitating internalization of extrinsic motivation. J Nutr Educ Behav. 2016;48:311-317.

46. Barkin SL, Gesell SB, Po'e EK, Escarfuller J, Tempesti T. Culturally tailored, family-centered, behavioral obesity intervention for Latino American preschoolaged children. Pediatrics. 2012;130:445-456.

47. University C. Parent Workshops Healthy Children, Healthy Families: Parents Making a Difference! Food and Nutrition Education in Communities 2013; https://www.fnec.cornell.edu/Our_Initiatives/CHANCE_HCHF.cfm. Accessed 05/10/15.

48. Dickin KL, Hill TF, Dollahite JS. The Collaboration for Health, Activity, and Nutrition in Children's Environments (CHANCE): A Program Integrating 
Parenting and Nutrition Behavioral Education Improves Food, Active Play, and Parenting Practices in Low-income Families. Faseb J. 2010;24.

49. Dickin KL, Hill TF, Dollahite JS. Practice-Based Evidence of Effectiveness in an Integrated Nutrition and Parenting Education Intervention for Low-Income Parents. J Acad Nutr Diet. 2014;114(6):945-950.

50. Lent M, Hill TF, Dollahite JS, Wolfe WS, Dickin KL. Healthy children, healthy families: parents making a difference! A curriculum integrating key nutrition, physical activity, and parenting practices to help prevent childhood obesity. $J$ Nutr Educ Behav. 2012;44(1):90-92.

51. Dickin KL, Lent M, Lu AH, Sequeira J, Dollahite JS. Developing a Measure of Behavior Change in a Program to Help Low-Income Parents Prevent Unhealthful Weight Gain in Children. J Nutr Educ Behav. 2012;44(1):12-21. 


\section{APPENDIX B \\ EXTENDED METHODOLOGY}

\section{Methods}

\section{Study Design}

The study utilized a non-experimental, within-subjects pre/post design. Parents of 3-11-year-old children participated in the evidence-based 8-week Healthy Children, Healthy Families (HCHF) curriculum/workshop series, which was taught by community paraprofessionals (navegantes) primarily in Spanish. The 8-week intervention was delivered to a total of four groups of mothers (approximately 5-15 mothers/group) between April and December 2015. The curriculum is focused on parenting techniques to improve family health behaviors including healthy eating, physical activity, and positive parenting practices.

The current study involved a community partnership with Clínica Esperanza/Hope Clinic (CEHC), a free healthcare clinic located in the Olneyville area of Providence, RI. The clinic provides free healthcare services to the uninsured, and also provides community health programs delivered by trained paraprofessional educators, or navegantes. As an existing community platform for health interventions, CEHC was chosen as the community partner for this study, and was the primary setting for the delivery of the intervention. All protocols of the proposed study were approved by the University of Rhode Island Institutional Review Board.

\section{Participants and Recruitment}

Eligible participants were parents or primary caregivers of children between the ages of 3-11 years, and willing to attend the weekly workshop sessions for 8 weeks. The 
target population was parents living in the Providence, Rhode Island area. In addition, we intended to reach a large percentage of at risk Hispanic parents given the demographics of this area.

Recruitment fliers (Appendix C) including study information were placed throughout the Olneyville area and distributed to organizations including community centers, local businesses, parks, libraries, and churches. In addition, the navegantes and community partners including healthcare clinics and current health-related programs helped do in person recruitment in the community. Interested parents were screened inperson or via telephone to determine eligibility. Navegantes would explain the program to parents, and answer questions about the study, in order to enroll participants. Recruitment efforts continued on a rolling basis by continuously recruiting eligible parents to participate in the next available group.

\section{Intervention}

The HCHF curriculum was taught by the navegantes (paraprofessional educators) employed through CEHC. Navegantes participated in a formal 2-day training on the HCHF curriculum, conducted by representatives from Cornell University. The training reviewed the foundations of the curriculum, answered frequently asked questions, addressed common barriers, and allowed for the practice of activities and lessons in the curriculum. The training also provided the navegantes with valuable background knowledge of the overall goals of the curriculum as well as tools and techniques surrounding curriculum flow, delivery, and evaluation.

The HCHF curriculum highlights 'paths to success' and 'keys to success' to facilitate healthy changes in families (Appendix D). ${ }^{1,2}$ These paths and keys to success, 
which serve as the backbone of the HCHF curriculum, highlight several positive diet behaviors and food parenting practices, and encourage parents to use these practices with their families at home. The six paths to success are: (1) Drinking water or milk instead of sweetened beverages, (2) Eating more vegetables and fruits (3) Playing actively, (4) Eating fewer high-fat, high-sugar foods, (5) Limiting TV and computer time, and (6) Having sensible servings. ${ }^{1,2}$ The keys to success include setting a good example for their child (showing/modeling), offering healthy choices within limits (guiding), helping children feel good about themselves (supporting), and making healthy choices easier (shaping). ${ }^{1,2}$ By integrating health education with parental support and tools to promote firm and responsive parenting, HCHF is a curriculum tailored to the specific needs of parents of 3 to 11-year old children.

The HCHF curriculum addresses health education topics surrounding diet, activity, and the home environment. The curriculum includes problem-solving strategies for health-related behavior change, and utilizes parenting scenarios and role-play to address barriers to behavior change. ${ }^{1,2}$ Specifically, the curriculum focuses on strategies that parents can use to improve their food parenting practices, including emphasizing their child's role in food preparation, encouraging their children to eat a balanced and varied diet, and modeling healthy eating behaviors to their children (Appendix E). In addition, each session also included an active play break, featuring a family-friendly activity that parents can do with their families at home (Appendix F). ${ }^{1,2}$ Every session includes a healthy recipe for parents to taste (Appendix G), and a weekly prize/incentive, such as pedometers or cooking utensils (Appendix H). For weekly goal-setting, at the end 
of each session parents identified a 'healthy step' or goal for the week ahead (Appendix I). ${ }^{1,2}$

To assess parent participation, attendance was recorded at each session. Study completers were considered for data analysis if they attended at least five out of the eight class sessions. To assess fidelity of the intervention, a portion of the HCHF sessions were observed. Out of the 32 sessions (8 sessions/group, 4 groups total), 19 sessions, or 59\% were observed. At least 2 sessions/group were observed. Fidelity assessment was conducted by a trained research assistant using previously developed observation checklists corresponding with each lesson/session of the HCHF intervention ${ }^{1}$ (Appendix J). Each lesson plan of the HCHF intervention divides into 4 categories, (1) Anchor, (2) Add, (3) Apply, and (4) Away. The observational checklist assessed completion of each of these domains for each lesson, and provides space where researchers can comment on what was changed, and areas for improvement. The observation tool also includes rubrics assessing the educators' delivery of the program and ability to facilitate the group, in addition to how group member's responded to the intervention. Using the completed observation checklist, intervention fidelity was high, indicating that the navegantes delivered the intervention as it was intended based on the protocol of the HCHF curriculum.

\section{Procedures}

Prior to the first session, baseline measures for each group of participants were collected. On the day of the first session, each mother-child dyad arrived at CEHC before the proposed session start time to complete baseline measures. All study materials were available in both English and Spanish. Mothers completed a consent form for themselves 
(Appendix K) and a written permission form their child if their child was under 7 years of age. Children who were over 7 years of age completed an assent form. Mothers then completed a baseline survey, which consisted of demographic questions, questions from the Comprehensive Feeding Practices Questionnaire (CFPQ), and the 16-item HCHF behavior checklist (Appendix L). Once mothers completed the survey, both mother and child were led to a separate area where a research assistant measured and recorded their baseline height and weight measurements (Appendix M). Once height and weight measurements of each mother-child dyad were completed, session one began. Although the focus of this intervention was for the mothers, mothers were encouraged to bring their children to the sessions where complimentary child care and/or a separate nutrition curriculum was delivered to the children. Mothers were compensated for their time with a $\$ 10$ gift card at the end of the first session. Mother-child dyads then returned to CEHC weekly for a total of eight sessions to complete the intervention. On the last week (session 8), the survey and measurement process described above was repeated to collect post-intervention data. Mothers were compensated for their time with a $\$ 40$ gift card at the end of the last session. In addition to completing a post-intervention survey, mothers also completed an evaluation survey from the HCHF curriculum which evaluated their opinions of the program (Appendix N).

\section{Measures}

\section{Anthropometrics}

Standing height and weight measurements of each parent-child dyad were taken using standardized procedures. ${ }^{3}$ Measurements were taken in a private area to assure confidentiality of measurements and to increase the comfort of participants. Each parent- 
child dyad was instructed to wear light clothing and remove footwear, and if applicable, asked to take down their hair to ensure measurement accuracy. Each parent and child had measurements (height and weight) taken twice to confirm measurement precision. Height measurements were rounded to the nearest $0.5 \mathrm{~cm}$, with a requirement of two measurements within $0.5 \mathrm{~cm}$ of one another. If the difference between the first two measurements was greater than $0.5 \mathrm{~cm}$, additional measurements were taken until an accurate measurement is reached, that is, two values within $0.5 \mathrm{~cm}$ of each other. For weight, the two measurements were required to be within $0.5 \mathrm{lb}$. of one another. If the difference between the first two measurements was greater than $0.5 \mathrm{lb}$., additional measurements were taken until there were two values within $0.5 \mathrm{lb}$. of one another. Height was measured using a portable stadiometer (Seca 213). Weight was measured using a calibrated digital scale (Seca 813). To assess parent BMI, the mean calculation for weight and height for each data collection point was used to calculate a BMI score (pre and post). For children, using the means for height and weight for both pre and post assessment, in addition to their date of birth and sex, a BMI z-score and BMI-percentile was calculated to assess changes in BMI.,

Survey Protocol

The survey was designed to be self-administered and consisted of 84 questions. Although it was designed to be self-administered, each participant was asked if they needed assistance completing the survey. If the participant needed assistance, a bilingual research assistant or navegante read questions aloud to ensure the participant understood each question and answer option. Parents answered each question as it pertains to their child involved in the study. If a parent has more than one child between ages 3-11, they 
were instructed to answer questions about the youngest child within the 3-11 age range. The survey took participants approximately 20-30 minutes to complete.

\section{Demographic Questionnaire}

The first section of the baseline survey consisted of 19 demographic questions. The following data was collected from mothers: age, sex, ethnicity, race, education level, number of children, ages of children, living with spouse, marital status, if they were born in the U.S., number of years in the U.S., employment status, number of jobs, health insurance status, annual household income, child date of birth, and child gender. In addition to the demographic questions, there was one question about the perceived weight status of their child, where parents are asked to circle one of seven figures/silhouettes (seven for each gender) that best represents their child, as previously described. ${ }^{6}$ Comprehensive Feeding Practices Questionnaire (CFPQ)

Self-reported food parenting practices were assessed using 29 questions from the previously validated Comprehensive Feeding Practices Questionnaire (CFPQ) that showed high internal consistency of the subscales ${ }^{7}$. For the purpose of this study only seven of the 12 subscales were used, including modeling (4 items), involvement (3 items), encouraging balance and variety (4 items), and teaching about nutrition. ${ }^{41}$ Examples for the 'encouraging balance and variety' subscale are "I encourage my child to eat a variety of foods," for the 'environment' subscale, "I keep a lot of snack food (potato chips, Doritos, cheese puffs) in my house" and for the 'involvement' subscale "I involve my child in planning family meals." ${ }^{77}$ Each question from the CFPQ has 5 answer options, ranging on a scale from disagree (1), disagree slightly (2), neutral (3), slightly agree (4), to agree (5). ${ }^{7}$ Thus, a higher score on each subscale indicates a higher frequency of the 
corresponding practice. One item indicates lower frequency of the feeding practice, and this item was reverse coded prior to scoring. Subscale means were calculated for seven subscales, and changes in subscale means pre/post will be assessed. The CFPQ subscales and corresponding items for the primary and secondary outcomes of this study are listed in Appendix $\mathrm{O}$.

\section{Healthy Children, Healthy Families Behavior Checklist (HCHF-BC)}

Measures of self-reported parent and child diet, physical activity, and screen time behaviors were assessed using the previously used HCHF behavior checklist. ${ }^{8}$ The 16 item behavior checklist assessed frequency of parent and child health behaviors, including diet habits (11 items) and physical activity/screen time behaviors (3 items). ${ }^{8}$ For example, "How often do your children play actively for at least 60 minutes a day?" and "How many days a week do you usually eat vegetables?"8 Each item was assessed using a 5-point scale with answers ranging on frequency specific to each question, starting with the least frequent answer option to the most frequent. For example, for the question "How often do your children play actively for at least 60 minutes a day?" the answer options range from (1) once in a while, (2) 1-2 days each week, (3) 3-4 days each

week, (4) 5-6 days each week, to (5) every day. Items were scored 1-5 with a higher total score indicating higher frequency of the corresponding behavior. The HCHF-BC items organized by construct are listed in Appendix P.

\section{Statistical Analysis}

Statistical analysis was performed using SPSS version 23. Descriptive statistics for study variables were calculated including means and standard deviations for continuous variables and frequencies and percentages for categorical variables. Shapiro- 
Wilk test was used to analyze normality of the data. Thirty-seven percent $(n=15)$ of participating mothers were lost to follow-up and did not complete the full intervention or post-intervention measures. To address the missing data due to participants lost to follow up, a multiple imputation analysis for missing data was run to impute missing data values for study outcomes. A missing value analysis with all outcome variables, in addition to all demographic variables that may provide information on the trends of these values was created. This included all post-intervention outcomes from the HCHF-BC and the CFPQ, in addition to demographic variables (age, number of children). Multiple imputation analysis was used to impute missing data values from participants lost to follow up for post-intervention outcomes from the HCHF-BC and CFPQ, using demographic variables (listed above) as predictors in the model. Based on previous literature, ${ }^{9-11}, 140$ imputations were used. Pooled values from the data set with imputed values were used for data analysis. Paired samples t-tests were performed to assess for statistically significant changes pre/post intervention. Significance level was set at $\mathrm{p}<0.05$. Results from the analysis of both the original and imputed dataset were compared for trends in the data following the analysis. 


\section{References- Extended Methodology}

1. University C. Parent Workshops Healthy Children, Healthy Families: Parents Making a Difference! Food and Nutrition Education in Communities 2013; https://www.fnec.cornell.edu/Our_Initiatives/CHANCE_HCHF.cfm. Accessed 05/10/15.

2. Dickin KL, Hill TF, Dollahite JS. The Collaboration for Health, Activity, and Nutrition in Children's Environments (CHANCE): A Program Integrating Parenting and Nutrition Behavioral Education Improves Food, Active Play, and Parenting Practices in Low-income Families. Faseb J. 2010;24.

3. Lohman TG. Advances in Body Composition Assessment. Current Issues in Exercise Science Series, Monograph No. 3. Champaign, IL: Human Kinetics Publishers, 1992:200-201.

4. Must A, Anderson SE. Body mass index in children and adolescents: considerations for population-based applicants. Int J Obes. 2006;30:590-594.

5. The Children's Hospital of Philadelphia. Pediatric Z-Score Calculator. http://stokes.chop.edu/web/zscore/. Accessed April 7, 2014.

6. Killion L, Hughes SO, Wendt JC, Pease D, Nicklas TA. Minority mothers' perceptions of children's body size. Int J Pediatr Obes. 2006;1:96-102.

7. Musher-Eizenman D, Holub S. Comprehensive feeding practices questionnaire: Validation of a new measure of parental feeding practices. J Pediatr Psychol. 2007;32:960-972.

8. Dickin KL, Lent M, Lu AH, Sequeira J, Dollahite JS. Developing a Measure of Behavior Change in a Program to Help Low-Income Parents Prevent Unhealthful Weight Gain in Children. J Nutr Educ Behav. 2012;44(1):12-21. 


\section{APPENDIX C}

\section{RECRUITMENT FLIER}

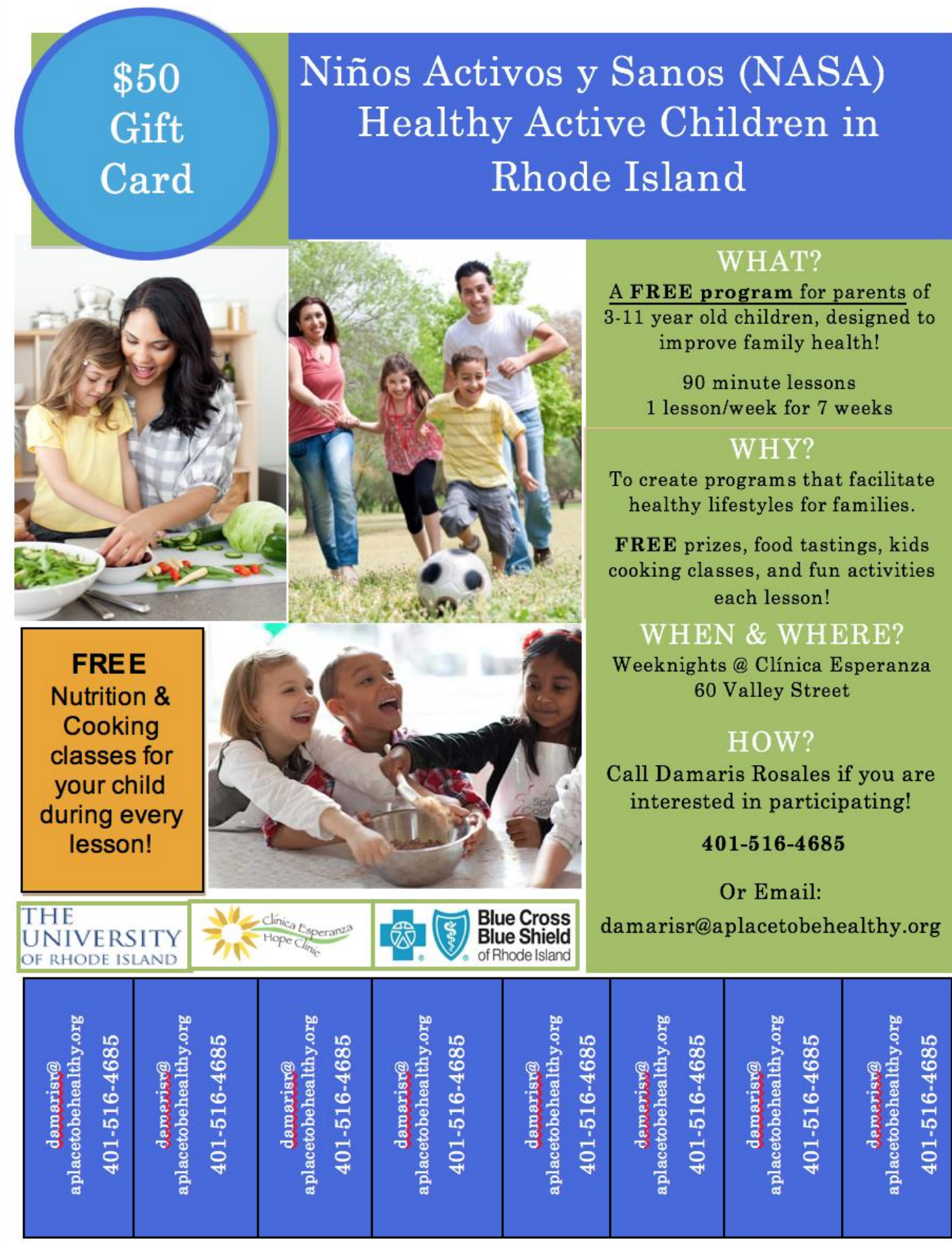


PATHS AND KEYS TO SUCCESS USED IN THE HCHF CURRICULUM,29
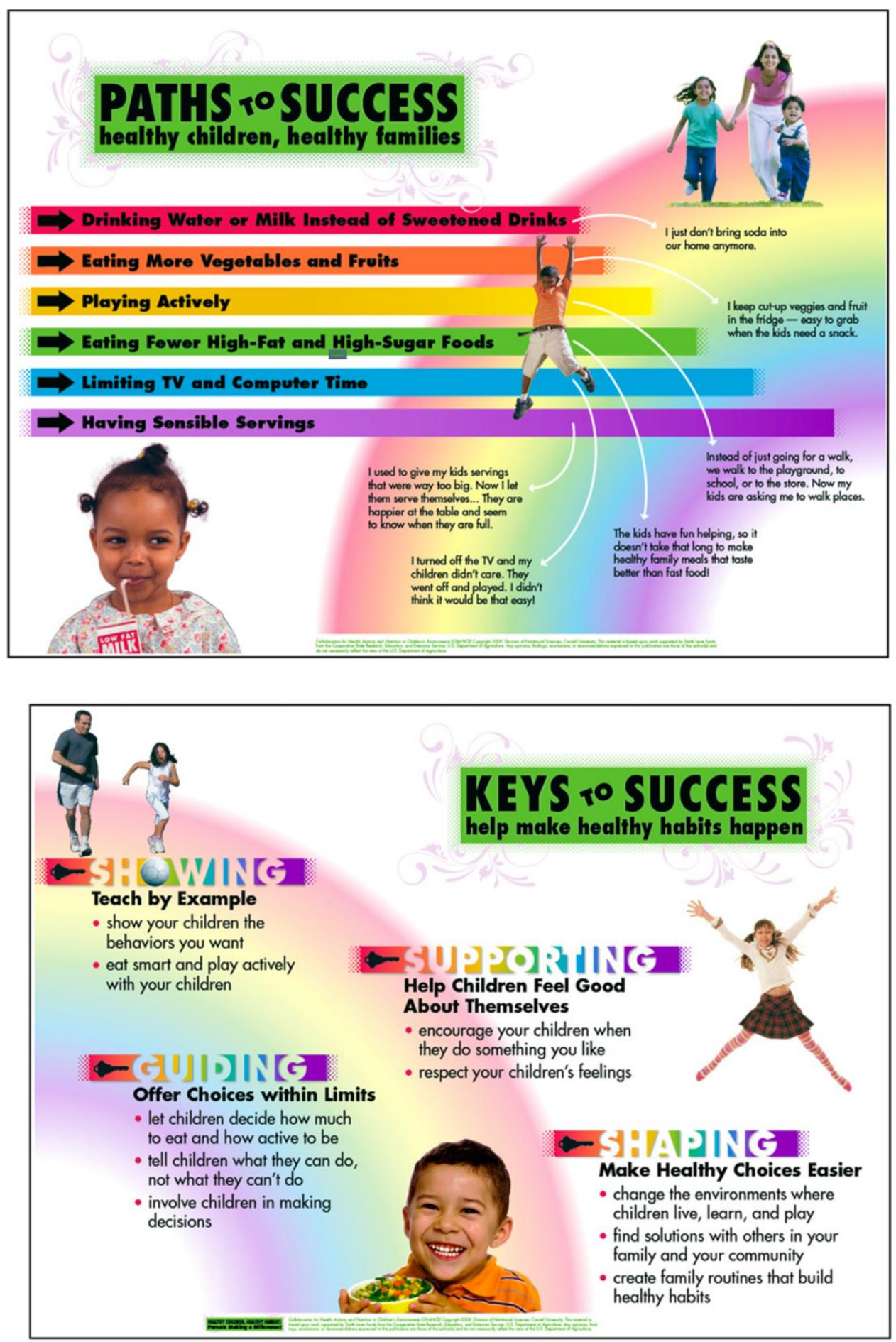
APPENDIX E

\section{EXAMPLE OF PARENTING PRACTICES ENCOURAGED IN HCHF CURRICULUM}

\section{Quick Ways to Make Vegetables and Fruits Fun for Children}

Cut fruit and veggies in different shapes

- Cut apples in half side-ways to see the "star" in the middle.

- Slice carrots into "coins" and let them count their money before they eat it.

Do-it-yourself fruit or vegetable kabobs

- Let children make their own fruit kabobs, putting small pieces of various fresh or canned fruit onto toothpicks.

- Try using vegetables instead!

Get children involved

- Let children sprinkle cinnamon on applesauce.

- Let children dip vegetables and fruits into simple low-fat dips or dressings.

- Spread peanut butter on celery or apple slices and let children add raisins.

- Let your child plan the dinner vegetables or what goes into the salad.

- Have your child help prepare dinner

- Let your child pick out a "new veggie or fruit of the week" while shopping.

- Decorate plates with vegetable or fruit slices.
Add more veggies and fruits to meals

- Buy dried and canned fruits and frozen and canned vegetables when they're on sale, so you always have some on hand.

- Serve fruit on breakfast cereal, or add to pancakes or waffles.

- Put whole, cut up, or canned fruit (drain juice off) on the table for dessert.

- Put vegetables on pizza.

- Add vegetables to spaghetti sauce.

- Add extra vegetables such as frozen peas or sliced carrots to Ramen type soups.

- Add color to salads by adding a variety of vegetables or fruits.

Add more veggies and fruits to snacks

- Add fruit to low-fat plain or vanilla yogurt.

- Keep clear bags of cut-up fruits and veggies in the front of the fridge where your child can easily grab them.

- Try applesauce to replace some oil when baking muffins or cakes.

- Offer raisins or other dried fruits instead of candy! 
APPENDIX F

EXAMPLE OF WEEKLY ACTIVE PLAY BREAK

Healthy Children, Healthy Families Session 6

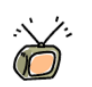

Sit Less: Reducing Screen Time

\section{Active Play Break: Balloon Toss (5-10 min)}

Instruct participants in wearing and using a pedometer, and tell them they can borrow it for the week. See facilitator guide for instructions.

Materials: A balloon blown up for each participant. Provide another one or two, not blown up, for each to take home and use with their children. Remind participants that balloons should not be used with children under the age of three.

Variations:

- Have partners switch halfway through or join with 2 other partners so that they have 4 people trying to keep two balloons aloft.

- Have participants keep the balloons aloft without using their hands.

- Have participants join hands and keep all their balloons aloft without letting go of their hands.
Let's try something simple, fun and active that children will enjoy doing instead of screen time.

First, let's all put on a pedometer, or step counter, so that we can measure how many steps we take during this game.

Find a partner.

When I say, "go," do everything you can to keep your balloon in the air for 3 minutes, until I stay "stop".

Do not let the balloon touch the floor.

? What did you think of this activity? What would your children think of it?

? How many steps did you take?

Keeping a balloon up is a fun way to play actively When your children do watch TV they might even enjoy doing this during commercials!

Think about how many minutes you and your children would be active if you did this during every commercial!

? How long is a typical commercial? (2-3 minutes)

? How many commercial breaks? (4-5, so $8-15$ minutes total) 
EXAMPLE OF WEEKLY RECIPE PROVIDED AT INTERVENTION

\section{Taco Salad with Cilantro Lime Dressing}

Ingredients

- 5 cups chopped lettuce (spinach, romaine)

- $3 / 4$ cup tomatoes, chopped

- $3 / 4$ cup corn (canned, frozen, or fresh)

- 3/4 cup canned black beans, drained and rinsed

- 2 tablespoons cilantro, chopped

- 1/4 cup tortilla chips, crushed

- Optional: Low-Fat Cheese, Avocado, Onion, Radish

Dressing

- 1 cup cilantro

- $1 / 2$ cup plain low-fat yogurt

- 2 cloves garlic

- Juice of 1 lime

- Pinch of salt

- $1 / 4$ cup olive oil

- 2 tablespoons apple cider vinegar

Directions

1. To make dressing, combine ingredients in a bowl and whisk, or combine in a food processor.

2. Combine salad ingredients in a bowl and toss together. Add dressing and toss to combine.

Recipe from:

http://damndelicious.net/2014/01/10/southwestern-chopped-salad-cilantro-lime-dressing/ 


\section{APPENDIX H}

LIST OF WEEKLY PRIZES FOR PARTICIPANTS

\begin{tabular}{|c|c|c|}
\hline Session & Incentive & Connection to HCHF \\
\hline 1 & $\$ 10$ gift card & Financial Incentive \\
\hline 2 & Water Bottle & $\begin{array}{c}\text { Drinking Water Instead of } \\
\text { Sugar Sweetened } \\
\text { Beverages }\end{array}$ \\
\hline 3 & $\begin{array}{c}\text { MyPlate } \\
\text { Shopping List }\end{array}$ & $\begin{array}{c}\text { Encourage Balance \& } \\
\text { Variety }\end{array}$ \\
\hline 4 & Pedometer & Playing Actively \\
\hline 5 & Spatula & Cooking Healthy Meals \\
\hline 6 & Kickball & Playing Actively \\
\hline 7 & Serving Bowls & Autonomy \& Family Meals \\
\hline 8 & $\$ 40$ gift card & Financial Incentive \\
\hline
\end{tabular}




\section{APPENDIX I}

EXAMPLE OF WEEKLY GOAL SETTING WORKSHEET

Healthy Children, Healthy Families Session 3

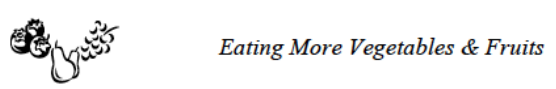

\section{Session 3 - Take a Healthy Step!}

Today's path: Eating more vegetables and fruits

Steps you could take this week:

$\square$ Teaching by example and eating more vegetables and fruits myself

Putting cut-up vegetables that my children like on the table as a side dish

$\square$ Introducing a new vegetable or fruit and respecting the feelings of my family about trying the new food

$\square$ Letting my child pick a new vegetable or fruit at the store for the family to try

Asking my child to help plan or prepare a vegetable or fruit snack

Or pick your own step:

Key to success that can help:

Showing Teach by example

Supporting Help children feel good about themselves

Guiding Offer choices within limits

Shaping Make healthy choices easier 


\section{APPENDIX J}

\section{EXAMPLE OF FIDELITY OBSERVATION CHECKLIST}

\section{Session 3: Eating More Vegetables and Fruits}

2015-2016 HCHF Observations Form

Site: RI Series\# Agency Partner/Location of class:

Date: No. attending today: Time started: Time ended:

Facilitators:

Observers/visitors:

1. Please note how each task went.

\begin{tabular}{|c|c|c|c|}
\hline Session Task & Did & Changed & $\begin{array}{l}\text { Successes or } \\
\text { Challenges? } \\
\text { Comments? }\end{array}$ \\
\hline \multicolumn{4}{|l|}{ Review of Previous Session } \\
\hline \multicolumn{3}{|c|}{ Task 1: Veggies \& Fruits - How much to eat? } & \\
\hline \multicolumn{3}{|l|}{$\begin{array}{r}\text { Anchor: Active Play Break } \\
\text { Veggie Toss }\end{array}$} & \\
\hline \multicolumn{3}{|l|}{ Add } & \\
\hline \multicolumn{3}{|l|}{ Apply } & \\
\hline \multicolumn{3}{|l|}{ Away } & \\
\hline \multicolumn{3}{|c|}{ Task 2: Strategies to Eat More Veggies \& Fruits } & \\
\hline \multicolumn{3}{|l|}{$\begin{array}{l}\text { Anchor: Food Activity } \\
\text { Vegetable \& Fruit Dips }\end{array}$} & \\
\hline \multicolumn{3}{|l|}{ Add (1) } & \\
\hline \multicolumn{3}{|l|}{ Apply (1) } & \\
\hline \multicolumn{3}{|l|}{ Add (2) } & \\
\hline \multicolumn{3}{|l|}{ Apply (2) } & \\
\hline \multicolumn{3}{|l|}{ Away } & \\
\hline Take a Healthy Step! & & & \\
\hline
\end{tabular}




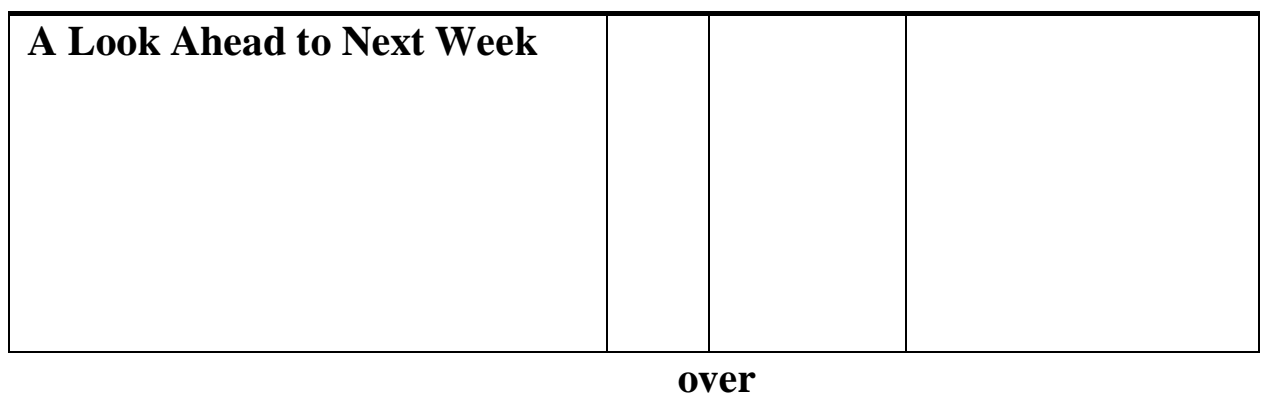

2. Changes to Session: *If you checked yes above, please give details here. Why were changes made? Please be specific.

3. Observations: Record observations or responses that indicate successes experienced by participants so far (include changes in attitudes, knowledge, and skills and/or behaviors)

\section{For Next Meeting}

a. Take a Healthy Step: What steps would participants like to try?

b. Looking Ahead: What types of snacks do participants and their families like?

\section{Participant questions/requests for follow-up:}




\section{Please circle the number corresponding to your response. Please comment on each aspect below.}

Facilitators covered the lesson content within the appropriate time frame.

\begin{tabular}{ccccc}
1 & 2 & 3 & 4 & 5 \\
\hline Ran out of time & & & & Covered all content at a comfortable pace
\end{tabular}

Comments:

Facilitators engaged participants and invited them to share, but moved on in a timely manner.

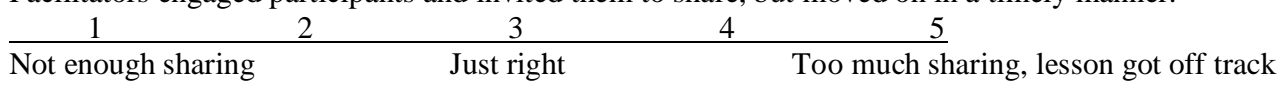

Comments:

Facilitators were comfortable handling questions related to nutrition.

\begin{tabular}{ccccc}
1 & 2 & 3 & 4 & 5 \\
\hline Uncomfortable & & & & Very comfortable
\end{tabular}

Comments:

Facilitators were comfortable handling questions related to parenting.

\begin{tabular}{ccccc}
1 & 2 & 3 & 4 & 5 \\
\hline Uncomfortable & & & & Very comfortable
\end{tabular}

Comments:

Supplies and materials needed were available.

\begin{tabular}{ccccc}
1 & 2 & 3 & 4 & 5 \\
\hline Were not available & & & & Were all available
\end{tabular}

Comments:

Facilitators connected the workshop content to participant's lives using examples from participants.

\begin{tabular}{ccccc}
1 & 2 & 3 & 4 & 5 \\
\hline Did not connect & & & & Good connections
\end{tabular}

Comments:

Facilitators worked as a team

$\frac{1}{\text { Lacking teamwork }}$

2

3

34

Comments:

\section{Strengths of educator:}

\section{Suggestions for change. How about...}




\section{Please circle the number corresponding yo your response. Please comment on each aspect below.}

\section{PARTICIPANT BEHAVIOR:}

At least one participant expressed a belief during the lesson.

$\begin{array}{lcccr}1 & 2 & 3 & 4 & 5 \\ \begin{array}{l}\text { Not enough sharing } \\ \text { Comments: }\end{array} & \text { some sharing } & \text { most participants shared }\end{array}$

Comments:

Participants demonstrated a sense of understanding of the lesson.

\begin{tabular}{lllll}
1 & 2 & 3 & 4 & 5 \\
\hline Did not understand & & & & Understood everything
\end{tabular}

Comments:

The participants as a whole do not appear bored vs. not bored.

$\begin{array}{lllcc}1 & 2 & 3 & 4 & 5 \\ \text { Very Bored } & & & & \text { Very Enthusiastic } \\ \text { Comments: } & & & \end{array}$

Comments:

Participants are attentive to the paraprofessionals.

\begin{tabular}{lccc}
1 & 3 & 4 & 5 \\
\hline Not attentive, no connection & & Very attentive \\
Comments:
\end{tabular}

Comments:

Participants are open and comfortable during discussion.

\begin{tabular}{lllll}
1 & 2 & 3 & 4 & 5 \\
\hline Uncomfortable & & & Very comfortable \\
Comments: & & &
\end{tabular}

Comments:

Participants are respectful of one another.

\begin{tabular}{lrrrr}
1 & 2 & 3 & 4 & 5 \\
\hline Disrespectful & & & & Very respectful
\end{tabular}

Comments:

\section{Highlights of participant behavior:}

\section{Suggestions for change:}




\section{APPENDIX K}

\section{PARENTAL CONSENT FORM}

\section{$\mathrm{THE}$ UNIVERSITY OF RHODE ISLAND}
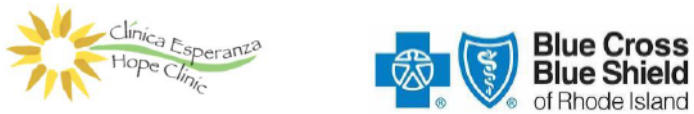

Consent for Participation

THE UNIVERSITY OF RHODE ISLAND

Niño's Activos y Sanos (NASA): Healthy Active Children in Rhode Island

You have been invited to take part in a research project described below. The researcher will explain the project to you in detail. You should feel free to ask questions. If you have more questions later, Alison Tovar, $\mathrm{PhD}$, the person mainly responsible for this study, (401) 874-9855, will discuss them with you. You must be at least 18 years old to be in this research project.

\section{Description of this project:}

Niño's Activos y Sanos (NASA) is a project organized by the University of Rhode Island, Blue Cross Blue Shield of Rhode Island, and the Clinica Esperanza/Hope Clinic $(\mathrm{CEHC})$. This project is designed to target and improve the health of children and their families in the Providence area.

This project uses the Healthy Children Healthy Families (HCHF) curriculum. This curriculum has been designed to inform parents/caretakers of young children by providing parenting practices that support children's healthy food and active play choices. We are asking you to participate in lessons, fill out a pre and post survey, receive text messages with follow-up information from the lessons, and participate in height and weight measurements. Your input will help develop future HCHF programs, and will provide useful information for you and your family.

What will happen if I decide to participate in the study?

If you agree to participate in this study, the following will happen:

1. You will participate eight $\mathrm{HCHF}$ lessons that equal one HCHF curriculum Lessons will be once per week, for a total of 8 weeks. Each lesson is about 90 minutes. Six to eight parents/caretakers will be asked to participate in each group. During the group sessions, your child/children can attend childcare and/or participate in cooking lessons. In between the group lessons, the navegantes who will be teaching the lessons will text you useful information to remind you what you learned and to remind you about next group dates.

2. During the project, there will be two evaluation days (week 1 and week 8 ). On these days, in addition to the scheduled lesson, we will take the following measurements.

a. Questions on nutrition, parenting practices, and demographics.

b. Height and weight (of both you and your child).

THE

UNIVERSITY

OF RHODE ISLAND IRB Approval Date 06/04/2015

DIVISION OF RESEARCH IRB Approval Expiration 03/04/20
AND ECONOMIC IR AND ECONOMIC
DEVELOPMENT 
3. Your group discussions and activities will be observed and notes will be taken. Any information gathered will be stored securely at the University of Rhode Island in Ranger Hall room 403.

Benefits or risks:

If you do decide to participate in this study, you will be helping research project staff to help develop programs to allow you to be a part of future nutrition education programs. The 8 lessons you attend will provide you with useful knowledge and skills to benefit your family's health. Parents who attend the sessions will be directly served as they will be the ones applying the information learned during the sessions and having discussions with other parents. Those who are indirectly served are the children and other family members of these parents. It is expected that the parents participating in this study will use the knowledge and strategies from class to apply them to their own home environments.

It is possible that some participants may suffer nervousness when weight measurements are recorded. To protect participant privacy and self-esteem, all measurements will be taken in private areas, not said aloud, and will not label anyone as overweight, obese, underweight, too thin, or anorexic. Measurements will be taken along with surveys (when they are being collected), so that the importance will not be on weight. We will not be saying any of the measurements aloud, but if you are at an unhealthy weight, we will be informing you by mailed letter. This letter will be sent after measurements are taken. In this letter we will provide places that may be helpful for you and ask you to talk about this information with your doctor.

\section{Confidentiality:}

All information about you will be kept confidential. Once we receive their information, the people working with Healthy Children Healthy Families will give you an ID number that will be used as their identification throughout the study. All names and personal information will be kept in locked files at the University of Rhode Island Ranger Hall 403, available only to the principal investigator and appropriate project staff. No one else will have access to their personal information. Evaluation Day measurements will be held in private areas. Height and weight measurements will not be said aloud, and measurements will be made along with the other measures so that the importance will not be on weight. You can stop participating at any time and you will no longer be contacted.

Notes will be retained for three years following the completion of the project and then destroyed.

Right to quit at any time:

The decision to participate in this study is voluntary and is up to you. You can quit the study at any time, simply by telling us that you no longer want to participate. If you decide not to participate in this study or leave during a lesson, nothing will happen and you will still be eligible for any services to which you are entitled.

THE 
In case of injury:

If this study causes you any injury, you should tell student investigator Laura Otterbach

(401) 575-1885. You should also write or call the office of the URI Vice-President for

Graduate Studies, Research, and Outreach, Suite 2, 70 Lower College Road, The University of Rhode Island, Kingston, RI 02881; Telephone (401) 874-4328.

Rights and Complaints:

If you are not satisfied with the way this study is performed, you may discuss your complaints with Alison Tovar (401) 874-9855 anonymously, if you choose. In addition, if you have questions about your rights as a research participant, you may contact the office of the Vice President for Research, 70 Lower College Road, Suite 2, University of Rhode Island, Kingston, Rhode Island, telephone: (401) 874-4328.

You have read the Consent Form. Your questions have been answered. Your signature on this form means that you understand the information and you agree to participate in this study.

Signature of Participant

Typed/printed Name

Date
Signature of Researcher

Typed/printed name

Date

Please sign both consent forms, and keep one for yourself.

THE

UNIVERSITY

RB \#HU1415-104

OF RHODE ISLAND IRB Approval Date 06/04/2015

AND ECONOMIC IRB Approval Expiration 03/04/2016 


\section{APPENDIX L}

\section{BASELINE SURVEY}

Niño's Activos y Sanos (NASA): Healthy Active Children in Rhode Island

Your name:

*If you have more than one child between the ages of 3-11, please answer questions based on the younger child in this age range:

Please answer the following questions about YOU.

1. How old are you? years

2. What is your sex?
Female

Male

3. Are you Hispanic or Latino?

No

Yes

$$
\rightarrow \text { If yes, country of origin: }
$$

4. What is your race? Please check all that apply.

White

African-American

American Indian/Alaskan Native

Asian

Native Hawaiian/Pacific Islander

More than once race

Wish not to answer/don't know

5. What is the highest level of education / schooling you have completed?

No formal schooling

Less than $8^{\text {th }}$ grade

$8^{\text {th }}$ grade or more, but less than high school

High school graduate (finished $12^{\text {th }}$ grade) or GED

Post high school trade or technical school

1-3 years of college

$\square$ College graduate/higher 
6. How many children between the ages of 2-13 years old live in your household?
1
2
3
$\square$
$\square 5$ or more

a. What ages? yrs.

7. Are you currently living with a spouse or partner?
Yes

No

8. What is your current marital status?
Never Married
Married
Separated
Divorced
Widowed

9. Were you born in the United States?

Yes

No

$\rightarrow$ If NO, how many years have you lived in the United States? years months

10. How would you describe your current employment status? Please check all that apply.

Employed full time (more than 35 hours/week)

Employed part time (less than 35 hours/week)

$\square$ Employed seasonally /on and off

Unemployed /looking for work

$\square$ Student

$\square$ Homemaker

$\rightarrow$ If employed, how many jobs do you currently have?

$\square \quad 1$
$\square \quad 2$
$\square \quad 3$
$\square \quad 4+$




\section{6-item HCHF-BC}

\begin{tabular}{|c|c|c|c|c|c|c|}
\hline 1) & $\begin{array}{l}\text { How many days each week do } \\
\text { you usually eat fruit (including } \\
\text { fresh, dried, frozen, and } \\
\text { canned)? }\end{array}$ & $\begin{array}{l}\text { Once } \\
\text { in a } \\
\text { while }\end{array}$ & $\begin{array}{c}1-2 \\
\text { days } \\
\text { each } \\
\text { week }\end{array}$ & $\begin{array}{c}\text { 3-4 days } \\
\text { each } \\
\text { week }\end{array}$ & $\begin{array}{c}\text { 5-6 days } \\
\text { each } \\
\text { week }\end{array}$ & $\begin{array}{c}\text { Every } \\
\text { day }\end{array}$ \\
\hline 2) & $\begin{array}{l}\text { How many days each week do } \\
\text { you usually eat vegetables } \\
\text { (including fresh, frozen, and } \\
\text { canned)? }\end{array}$ & $\begin{array}{l}\text { Once } \\
\text { in a } \\
\text { while }\end{array}$ & $\begin{array}{c}1-2 \\
\text { days } \\
\text { each } \\
\text { week }\end{array}$ & $\begin{array}{c}\text { 3-4 days } \\
\text { each } \\
\text { week }\end{array}$ & $\begin{array}{c}\text { 5-6 days } \\
\text { each } \\
\text { week }\end{array}$ & $\begin{array}{c}\text { Every } \\
\text { day }\end{array}$ \\
\hline 3) & $\begin{array}{l}\text { How often do you drink regular } \\
\text { (NOT diet) soda? }\end{array}$ & $\begin{array}{c}\text { Almost } \\
\text { never }\end{array}$ & $\begin{array}{c}1-3 \\
\text { days } \\
\text { each } \\
\text { week }\end{array}$ & $\begin{array}{c}\text { 4-6 days } \\
\text { each } \\
\text { week }\end{array}$ & $\begin{array}{c}\text { Once } \\
\text { each day }\end{array}$ & $\begin{array}{l}2 \text { or } \\
\text { more } \\
\text { times } \\
\text { each } \\
\text { day }\end{array}$ \\
\hline 4) & $\begin{array}{l}\text { How often do you use } 1 \% \text { milk, } \\
\text { skim milk, or low-fat yogurt? }\end{array}$ & Never & $\begin{array}{l}\text { Once } \\
\text { in a } \\
\text { while }\end{array}$ & $\begin{array}{c}\text { Once } \\
\text { each day }\end{array}$ & $\begin{array}{l}\text { Twice } \\
\text { each day }\end{array}$ & $\begin{array}{l}3 \text { or } \\
\text { more } \\
\text { times } \\
\text { each } \\
\text { day }\end{array}$ \\
\hline 5) & $\begin{array}{l}\text { How often are you physically } \\
\text { active for at least } 30 \text { minutes a } \\
\text { day - active enough that you } \\
\text { breathe a little harder or your } \\
\text { heart beats faster? This includes } \\
\text { brisk walking, dancing, and } \\
\text { playing actively with kids. }\end{array}$ & $\begin{array}{l}\text { Once } \\
\text { in a } \\
\text { while }\end{array}$ & $\begin{array}{c}1-2 \\
\text { days } \\
\text { each } \\
\text { week }\end{array}$ & $\begin{array}{c}\text { 3-4 days } \\
\text { each } \\
\text { week }\end{array}$ & $\begin{array}{c}\text { 5-6 days } \\
\text { each } \\
\text { week }\end{array}$ & $\begin{array}{l}\text { Every } \\
\text { day }\end{array}$ \\
\hline 6) & $\begin{array}{l}\text { How many days each week do } \\
\text { your children usually eat } \\
\text { vegetables (including fresh, } \\
\text { frozen, and canned)? }\end{array}$ & $\begin{array}{l}\text { Once } \\
\text { in a } \\
\text { while }\end{array}$ & $\begin{array}{c}1-2 \\
\text { days } \\
\text { each } \\
\text { week }\end{array}$ & $\begin{array}{c}\text { 3-4 days } \\
\text { each } \\
\text { week }\end{array}$ & $\begin{array}{c}\text { 5-6 days } \\
\text { each } \\
\text { week }\end{array}$ & $\begin{array}{l}\text { Every } \\
\text { day }\end{array}$ \\
\hline 7) & $\begin{array}{l}\text { How often do your children } \\
\text { drink regular (NOT diet) soda? }\end{array}$ & $\begin{array}{c}\text { Almost } \\
\text { never }\end{array}$ & $\begin{array}{c}1-3 \\
\text { days } \\
\text { each } \\
\text { week }\end{array}$ & $\begin{array}{c}\text { 4-6 days } \\
\text { each } \\
\text { week }\end{array}$ & $\begin{array}{c}\text { Once } \\
\text { each day }\end{array}$ & $\begin{array}{l}2 \text { or } \\
\text { more } \\
\text { times } \\
\text { each } \\
\text { day }\end{array}$ \\
\hline
\end{tabular}




\begin{tabular}{|c|c|c|c|c|c|c|}
\hline 8) & $\begin{array}{l}\text { How often do your children have } \\
1 \% \text { milk, skim milk, or low-fat } \\
\text { yogurt? }\end{array}$ & Never & $\begin{array}{l}\text { Once } \\
\text { in a } \\
\text { while }\end{array}$ & $\begin{array}{c}\text { Once } \\
\text { each day }\end{array}$ & $\begin{array}{c}\text { Twice } \\
\text { each day }\end{array}$ & $\begin{array}{l}3 \text { or } \\
\text { more } \\
\text { times } \\
\text { each } \\
\text { day }\end{array}$ \\
\hline 9) & $\begin{array}{l}\text { In a typical week, how often do } \\
\text { you let your children decide how } \\
\text { much food to eat? }\end{array}$ & $\begin{array}{c}\text { Almost } \\
\text { never }\end{array}$ & $\begin{array}{l}\text { Less } \\
\text { than } \\
\text { half the } \\
\text { time }\end{array}$ & $\begin{array}{l}\text { Half the } \\
\text { time }\end{array}$ & $\begin{array}{l}\text { More than } \\
\text { half the } \\
\text { time }\end{array}$ & $\begin{array}{l}\text { Almost } \\
\text { always }\end{array}$ \\
\hline 10) & $\begin{array}{l}\text { How much time do your children } \\
\text { spend watching TV, using the } \\
\text { computer, or playing video } \\
\text { games? }\end{array}$ & $\begin{array}{l}\text { Less } \\
\text { than } 1 \\
\text { hour } \\
\text { each } \\
\text { day }\end{array}$ & $\begin{array}{l}1-2 \\
\text { hours } \\
\text { each } \\
\text { day }\end{array}$ & $\begin{array}{c}\text { 3-4 } \\
\text { hours } \\
\text { each day }\end{array}$ & $\begin{array}{l}\text { 5-6 hours } \\
\text { each day }\end{array}$ & $\begin{array}{l}7 \text { or } \\
\text { more } \\
\text { hours } \\
\text { each } \\
\text { day }\end{array}$ \\
\hline 11) & $\begin{array}{l}\text { How often do your children play } \\
\text { actively for at least } 60 \text { minutes a } \\
\text { day - actively enough that they } \\
\text { breathe a little harder or their } \\
\text { hearts beat faster? }\end{array}$ & $\begin{array}{l}\text { Once } \\
\text { in a } \\
\text { while }\end{array}$ & $\begin{array}{l}1-2 \\
\text { days } \\
\text { each } \\
\text { week }\end{array}$ & $\begin{array}{c}\text { 3-4 days } \\
\text { each } \\
\text { week }\end{array}$ & $\begin{array}{c}\text { 5-6 days } \\
\text { each } \\
\text { week }\end{array}$ & $\begin{array}{c}\text { Every } \\
\text { day }\end{array}$ \\
\hline 12) & $\begin{array}{l}\text { How often do your children } \\
\text { usually eat take out, delivery, or } \\
\text { fast foods (such as burgers, fried } \\
\text { chicken, pizza, Chinese food)? }\end{array}$ & $\begin{array}{l}\text { Once } \\
\text { in a } \\
\text { while }\end{array}$ & $\begin{array}{l}1-2 \\
\text { days } \\
\text { each } \\
\text { week }\end{array}$ & $\begin{array}{c}\text { 3-4 days } \\
\text { each } \\
\text { week }\end{array}$ & $\begin{array}{c}\text { 5-6 days } \\
\text { each } \\
\text { week }\end{array}$ & $\begin{array}{c}\text { Every } \\
\text { day }\end{array}$ \\
\hline 13) & $\begin{array}{l}\text { How often do you eat together } \\
\text { with your children at least one } \\
\text { meal a day? }\end{array}$ & $\begin{array}{c}\text { Almost } \\
\text { never }\end{array}$ & $\begin{array}{l}1-2 \\
\text { days } \\
\text { each } \\
\text { week }\end{array}$ & $\begin{array}{c}\text { 3-4 days } \\
\text { each } \\
\text { week }\end{array}$ & $\begin{array}{l}\text { 5-6 days } \\
\text { each } \\
\text { week }\end{array}$ & $\begin{array}{c}\text { Every } \\
\text { day }\end{array}$ \\
\hline 14) & $\begin{array}{l}\text { In a typical month, how often are } \\
\text { high-fat or high-sugar snacks } \\
\text { available at home for your } \\
\text { children to eat? This includes } \\
\text { chips, candy, cookies, and } \\
\text { sweets. }\end{array}$ & $\begin{array}{c}\text { Almost } \\
\text { never }\end{array}$ & $\begin{array}{l}\text { Less } \\
\text { than } \\
\text { half the } \\
\text { time }\end{array}$ & $\begin{array}{l}\text { Half the } \\
\text { time }\end{array}$ & $\begin{array}{l}\text { More than } \\
\text { half the } \\
\text { time }\end{array}$ & $\begin{array}{l}\text { Almost } \\
\text { always }\end{array}$ \\
\hline
\end{tabular}




\begin{tabular}{|c|l|c|c|c|c|c|}
\hline 15) & $\begin{array}{l}\text { In a typical month, how often are } \\
\text { fruits available at home for your } \\
\text { children to eat? }\end{array}$ & $\begin{array}{c}\text { Almost } \\
\text { never }\end{array}$ & $\begin{array}{c}\text { Less } \\
\text { than } \\
\text { half the } \\
\text { time }\end{array}$ & $\begin{array}{c}\text { Half the } \\
\text { time }\end{array}$ & $\begin{array}{c}\text { More than } \\
\text { half the } \\
\text { time }\end{array}$ & $\begin{array}{c}\text { Almost } \\
\text { always }\end{array}$ \\
\hline 16) & $\begin{array}{l}\text { How many days each week do } \\
\text { your children usually eat fruit } \\
\text { (including fresh, dried, frozen, } \\
\text { and canned)? }\end{array}$ & $\begin{array}{c}\text { Once } \\
\text { in a } \\
\text { while }\end{array}$ & $\begin{array}{c}1-2 \\
\text { days } \\
\text { each } \\
\text { week }\end{array}$ & $\begin{array}{c}3-4 \text { days } \\
\text { each } \\
\text { week }\end{array}$ & $\begin{array}{c}\text { 5-6 days } \\
\text { each } \\
\text { week }\end{array}$ & $\begin{array}{c}\text { Every } \\
\text { day }\end{array}$ \\
\hline
\end{tabular}




\begin{tabular}{|l|l|l|l|l|l|}
\hline 1. Most of the food I keep in the house is healthy. & 1 & 2 & 3 & 4 & 5 \\
\hline $\begin{array}{l}\text { 2. I encourage my child to eat when hungry and stop } \\
\text { when full. }\end{array}$ & 1 & 2 & 3 & 4 & 5 \\
\hline $\begin{array}{l}\text { 3. My child should always eat all of the food on } \\
\text { his/her plate. }\end{array}$ & 1 & 2 & 3 & 4 & 5 \\
\hline $\begin{array}{l}\text { 4. I have to be sure that my child does not eat too } \\
\text { many high-fat foods. }\end{array}$ & 1 & 2 & 3 & 4 & 5 \\
\hline $\begin{array}{l}\text { 5. I offer my child his/her favorite foods in exchange } \\
\text { for good behavior. }\end{array}$ & 1 & 2 & 3 & 4 & 5 \\
\hline $\begin{array}{l}\text { 6. Even if my child doesn't like a certain food, I think } \\
\text { s/he should eat it. }\end{array}$ & 1 & 2 & 3 & 4 & 5 \\
\hline $\begin{array}{l}\text { 7. If I did not guide or regulate my child's eating, s/he } \\
\text { would eat too much of his/her favorite foods. }\end{array}$ & 1 & 2 & 3 & 4 & 5 \\
\hline $\begin{array}{l}\text { 8. Offering this child something to eat is one of the } \\
\text { best ways to stop his/her temper tantrums. }\end{array}$ & 1 & 2 & 3 & 4 & 5 \\
\hline $\begin{array}{l}\text { 9. I offer sweets (candy, ice cream, cake, pastries) to } \\
\text { my child as a reward for good behavior. }\end{array}$ & 1 & 2 & 3 & 4 & 5 \\
\hline $\begin{array}{l}\text { 10. If my child eats an unhealthy food, I limit his/her } \\
\text { eating of unhealthy foods for a while to make up } \\
\text { for it. }\end{array}$ & 1 & 2 & 3 & 4 & 5 \\
\hline 11.I encourage my child to try new foods. & 1 & 2 & 3 & 4 & 5 \\
\hline $\begin{array}{l}\text { 12. Iiscuss with my child why it's important to eat } \\
\text { healthy foods. }\end{array}$ & 1 & 2 & 3 & 4 & 5 \\
\hline $\begin{array}{l}\text { 13. My child must eat all of his/her dinner in order to } \\
\text { have dessert. }\end{array}$ & 1 & 2 & 3 & 4 & 5 \\
\hline $\begin{array}{l}\text { 14.I encourage my child to eat less so he/she won't } \\
\text { get fat. }\end{array}$ & 1 & 2 & 3 & 4 & 5 \\
\hline $\begin{array}{l}\text { 15. If I did not guide or regulate my child's eating, s/he } \\
\text { would eat too many junk foods. }\end{array}$ & 1 & 2 & 3 & 4 & 5 \\
\hline $\begin{array}{l}\text { 16.I give my child small helpings at meals to control } \\
\text { his/her weight. }\end{array}$ & 1 & 2 & 3 & 4 & 5 \\
\hline $\begin{array}{l}\text { 17. If my child eats more than usual at one meal, I try } \\
\text { to restrict his/her eating at the next meal. }\end{array}$ & 1 & 2 & 3 & 4 & 5 \\
\hline $\begin{array}{l}\text { 18. Irestrict the food my child eats that might make } \\
\text { him/her fat. }\end{array}$ & 1 & 2 & 3 & 4 & 5 \\
\hline $\begin{array}{l}\text { 19. There are certain foods my child shouldn't eat } \\
\text { because they will make him/her fat. }\end{array}$ & 1 & 2 & 3 & 4 & 5 \\
\hline
\end{tabular}




\begin{tabular}{|c|c|c|c|c|c|}
\hline $\begin{array}{l}20 . \text { I withhold sweets/dessert from my child in } \\
\text { response to bad behavior. }\end{array}$ & 1 & 2 & 3 & 4 & 5 \\
\hline $\begin{array}{l}\text { 21. If I make a variety of healthy foods available to my } \\
\text { child, I trust that } \mathrm{s} / \text { he will choose a healthy diet. }\end{array}$ & 1 & 2 & 3 & 4 & 5 \\
\hline 22. I encourage my child to eat a variety of foods. & 1 & 2 & 3 & 4 & 5 \\
\hline $\begin{array}{l}\text { 23. I discuss with my child the nutritional value of } \\
\text { foods. }\end{array}$ & 1 & 2 & 3 & 4 & 5 \\
\hline $\begin{array}{l}\text { 24. I have to be sure that my child does not eat too } \\
\text { much of his/her favorite foods. }\end{array}$ & 1 & 2 & 3 & 4 & 5 \\
\hline $\begin{array}{l}\text { 25. I don't allow my child to eat between meals } \\
\text { because I don't want him/her to get fat. }\end{array}$ & 1 & 2 & 3 & 4 & 5 \\
\hline $\begin{array}{l}\text { 26. I tell my child what to eat and what not to eat } \\
\text { without explanation. }\end{array}$ & 1 & 2 & 3 & 4 & 5 \\
\hline $\begin{array}{l}\text { 27. I have to be sure that my child does not eat too } \\
\text { many sweets (candy, ice cream, cake, or pastries). }\end{array}$ & 1 & 2 & 3 & 4 & 5 \\
\hline $\begin{array}{l}28 . \text { I model healthy eating for my child by eating } \\
\text { healthy foods myself. }\end{array}$ & 1 & 2 & 3 & 4 & 5 \\
\hline $\begin{array}{l}\text { 29. I often put my child on a diet to control his/her } \\
\text { weight. }\end{array}$ & 1 & 2 & 3 & 4 & 5 \\
\hline $\begin{array}{l}\text { 30. It is impossible to keep track of what my child eats } \\
\text { because he/she eats in so many places. }\end{array}$ & 1 & 2 & 3 & 4 & 5 \\
\hline $\begin{array}{l}\text { 31. If I try to guide or regulate my child's eating, it will } \\
\text { make him/her unhappy. }\end{array}$ & 1 & 2 & 3 & 4 & 5 \\
\hline $\begin{array}{l}\text { 32. I try to eat healthy foods in front of my child, even if } \\
\text { they are not my favorite. }\end{array}$ & 1 & 2 & 3 & 4 & 5 \\
\hline $\begin{array}{l}\text { 33. I try to show enthusiasm about eating healthy } \\
\text { foods. }\end{array}$ & 1 & 2 & 3 & 4 & 5 \\
\hline $\begin{array}{l}\text { 34. I show my child how much I enjoy eating healthy } \\
\text { foods. }\end{array}$ & 1 & 2 & 3 & 4 & 5 \\
\hline $\begin{array}{l}\text { 35. I feel that I have an important role in establishing } \\
\text { lifelong eating habits in my child. }\end{array}$ & 1 & 2 & 3 & 4 & 5 \\
\hline $\begin{array}{l}\text { 36. I feel responsible for determining portion sizes for } \\
\text { my child. }\end{array}$ & 1 & 2 & 3 & 4 & 5 \\
\hline $\begin{array}{l}\text { 37. I feel responsible for providing a healthy diet for } \\
\text { my child. }\end{array}$ & 1 & 2 & 3 & 4 & 5 \\
\hline $\begin{array}{l}\text { 38. I encourage my child to eat healthy foods before } \\
\text { unhealthy foods. }\end{array}$ & 1 & 2 & 3 & 4 & 5 \\
\hline 39. I tell my child that healthy food tastes good. & 1 & 2 & 3 & 4 & 5 \\
\hline 40. I involve my child in planning family meals. & 1 & 2 & 3 & 4 & 5 \\
\hline 41. I allow my child to help prepare family meals. & 1 & 2 & 3 & 4 & 5 \\
\hline $\begin{array}{l}\text { 42. I encourage my child to participate in grocery } \\
\text { shopping. }\end{array}$ & 1 & 2 & 3 & 4 & 5 \\
\hline
\end{tabular}




\begin{tabular}{|lcccccc|}
\hline & Never & Rarely & Sometimes & Often & Always \\
\hline My child refuses new foods at first & $\square$ & $\square$ & $\square$ & $\square$ & $\square$ \\
My child enjoys tasting new foods & $\square$ & $\square$ & $\square$ & $\square$ & $\square$ \\
$\begin{array}{l}\text { My child enjoys a wide variety of } \\
\text { foods }\end{array}$ & $\square$ & $\square$ & $\square$ & $\square$ & $\square$ \\
$\begin{array}{l}\text { My child is difficult to please with } \\
\text { meals }\end{array}$ & $\square$ & $\square$ & $\square$ & $\square$ & $\square$ \\
$\begin{array}{l}\text { My child is interested in tasting food } \\
\text { s/he hasn't tasted before }\end{array}$ & $\square$ & $\square$ & $\square$ & $\square$ & $\square$ \\
$\begin{array}{l}\text { My child decides that s/he doesn't like } \\
\text { a food, even without tasting it }\end{array}$ & $\square$ & $\square$ & $\square$ & $\square$ & $\square$ \\
\hline
\end{tabular}

1. What is your child's date of birth?

Day___Month____ /Year

2. What is your child's gender?

Female

Male

3. Choose the figure that best represents your child. Please circle one figure, based on whether your child is a boy or girl.

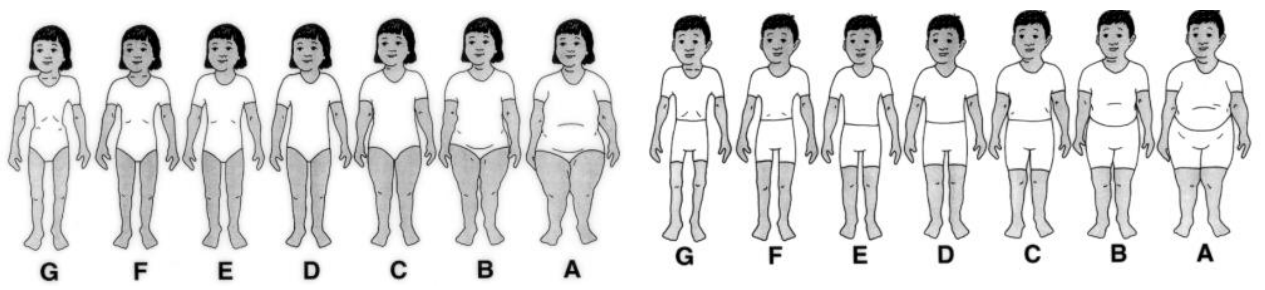


1. Do you have health insurance?

$\square$ No

Yes

1a) If yes, do you have Medicaid?

No

$\square$ Yes

2. What is your annual household income?

$\$ 15,000$ or less

$\$ 15,000-\$ 30,000$

$\$ 30,000-\$ 45,000$

More than $\$ 45,000$ 
ANTHROPOMETRIC MEASUREMENT RECORDING FORM

Niño's Activos y Sanos: Height and Weight Collection Sheet

\begin{tabular}{l|l|}
\hline \hline Today's Date: & $\begin{array}{l}\text { NOTES } \\
\text { If the hairstyle affects the height measurement ... } \\
\text { ID Code: }\end{array} \quad \begin{array}{l}\text { use a plastic ruler to estimate how much is contributed } \\
\text { by the hairstyle to the nearest half an inch: }\end{array}$
\end{tabular}

PARENT

\section{HEIGHT MEASUREMENT}

- Must have at least TWO measurements

- The three readings should be all within $1 / 2$ inch

of each other (round up)

$1^{\text {st }}$ measurement:

$2^{\text {nd }}$ measurement:

Additional:

$3^{\text {rd }}$ measurement:

$4^{\text {th }}$ measurement:

$5^{\text {th }}$ measurement:

$6^{\text {th }}$ measurement:

Recorder's Name:
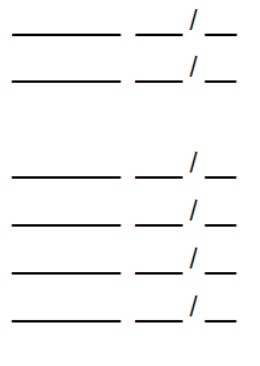

\section{WEIGHT MEASUREMENT}

- Must have at least TWO measurements

- The three readings should be all within $0.5 \mathrm{lb}$ of each other

$1^{\text {st }}$ measurement:

$2^{\text {nd }}$ measurement:

Additional:

$3^{\text {rd }}$ measurement:

$4^{\text {th }}$ measurement:

$5^{\text {th }}$ measurement:

$6^{\text {th }}$ measurement:

Recorder's Name:

\section{$\underline{\text { CHILD }}$}

I. HEIGHT MEASUREMENT

- Must have at least TWO measurements

- The three readings should be all within $1 / 2$ inch of each other (round up)

$1^{\text {st }}$ measurement:

$2^{\text {nd }}$ measurement:

Additional:

$3^{\text {rd }}$ measurement:

$4^{\text {th }}$ measurement:

$5^{\text {th }}$ measurement:

$6^{\text {th }}$ measurement:

Recorder's Name:
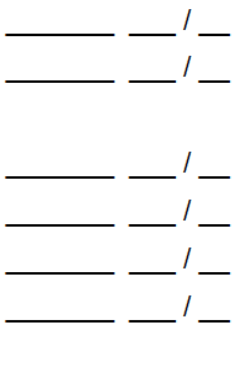

II. WEIGHT MEASUREMENT

- Must have at least TWO measurements

- The three readings should be all within $0.5 \mathrm{lb}$ of each other

$1^{\text {st }}$ measurement:

$2^{\text {nd }}$ measurement:

Additional:

$3^{\text {rd }}$ measurement:

$4^{\text {th }}$ measurement:

$5^{\text {th }}$ measurement:

$6^{\text {th }}$ measurement:

Recorder's Name: 


\section{APPENDIX N}

\section{HCHF PARTICIPANT PROGRAM EVALUATION FORM}

Healthy Children, Healthy Families Participant Evaluation Form

\begin{tabular}{|c|c|c|c|c|c|}
\hline $\begin{array}{l}\text { Circle the number that best describes how } \\
\text { much you agree with each sentence. }\end{array}$ & $\begin{array}{l}\text { Strongly } \\
\text { Disagree }\end{array}$ & Disagree & $\begin{array}{l}\text { Not } \\
\text { Sure }\end{array}$ & Agree & $\begin{array}{l}\text { Agree } \\
\text { Strongly }\end{array}$ \\
\hline $\begin{array}{l}\text { I enjoyed coming to Healthy Children, Healthy } \\
\text { Families sessions. }\end{array}$ & 1 & 2 & 3 & 4 & 5 \\
\hline $\begin{array}{l}\text { I learned a lot of new things in Healthy Children, } \\
\text { Healthy Families. }\end{array}$ & 1 & 2 & 3 & 4 & 5 \\
\hline $\begin{array}{l}\text { The educator(s) did a good job of teaching and } \\
\text { working with the group. }\end{array}$ & 1 & 2 & 3 & 4 & 5 \\
\hline $\begin{array}{l}\text { I would recommend Healthy Children, Healthy } \\
\text { Families to my friends and/or family. }\end{array}$ & 1 & 2 & 3 & 4 & 5 \\
\hline $\begin{array}{l}\text { What I learned in Healthy Children, Healthy } \\
\text { Families is useful for me and my family. }\end{array}$ & 1 & 2 & 3 & 4 & 5 \\
\hline $\begin{array}{l}\text { I felt very comfortable while participating in } \\
\text { Healthy Children, Healthy Families. }\end{array}$ & 1 & 2 & 3 & 4 & 5 \\
\hline $\begin{array}{l}\text { The number of sessions in the series ( } 8 \text { ) was just } \\
\text { right for me to learn the information. }\end{array}$ & 1 & 2 & 3 & 4 & 5 \\
\hline $\begin{array}{l}\text { The Healthy Children, Healthy Families topics } \\
\text { and activities were interesting and fun. }\end{array}$ & 1 & 2 & 3 & 4 & 5 \\
\hline $\begin{array}{l}\text { I learned new parenting skills that help me get } \\
\text { along better with my children. }\end{array}$ & 1 & 2 & 3 & 4 & 5 \\
\hline $\begin{array}{l}\text { The length of time the Healthy Children, Healthy } \\
\text { Families sessions lasted was fine for me. }\end{array}$ & 1 & 2 & 3 & 4 & 5 \\
\hline $\begin{array}{l}\text { The time that the sessions were held was } \\
\text { convenient for me. }\end{array}$ & 1 & 2 & 3 & 4 & 5 \\
\hline The location was convenient for me. & 1 & 2 & 3 & 4 & 5 \\
\hline
\end{tabular}

Comments (use back of form if needed):

13. What I liked best about Healthy Children, Healthy Families was:

14. Because of what I have learned, we are making these changes at home:

15. I would like to learn more about: 


\section{APPENDIX O}

\section{SUBSCALES AND CORRESPONDING ITEMS FROM THE CFPQ}

\section{FULL SUBSCALES ASSESSED:}

\section{Modeling}

- I model healthy eating for my child by eating healthy foods myself.

- I try to eat healthy foods in front of my child, even if they are not my favorite.

- I try to show enthusiasm about eating healthy foods.

- I show my child how much I enjoy eating healthy foods.

\section{Encouragement of Balance \& Variety}

- I encourage my child to try new foods.

- I encourage my child to eat a variety of foods.

- I encourage my child to eat healthy foods before unhealthy foods.

- I tell my child that healthy food tastes good.

\section{Involvement}

- I involve my child in planning family meals.

- I allow my child to help prepare family meals.

- I encourage my child to participate in grocery shopping.

\section{Teaching About Nutrition}

- I discuss with my child why it's important to eat healthy foods.

- I discuss with my child the nutritional value of foods.

- I tell my child what to eat and what not to eat without explanation. (R)

\section{Restriction for Health}

- If I did not guide or regulate my child's eating, s/he would eat too much of his/her favorite foods.

- If I did not guide or regulate my child's eating, s/he would eat too many junk foods.

- I have to be sure that my child does not eat too much of his/her favorite foods.

- I have to be sure that my child does not eat too many sweets (candy, ice cream, cake, or pastries).

\section{Restriction for Weight Control}

- I have to be sure that my child does not eat too many high-fat foods.

- I encourage my child to eat less so he/she won't get fat.

- I give my child small helpings at meals to control his/her weight.

- If my child eats more than usual at one meal, I try to restrict his/her eating at the next meal.

- I restrict the food my child eats that might make him/her fat. 
- There are certain foods my child shouldn't eat because they will make him/her fat.

- I don't allow my child to eat between meals because I don't want him/her to get fat.

- I tell my child what to eat and what not to eat without explanation.

\section{Food as Reward}

- I offer my child his/her favorite foods in exchange for good behavior.

- I offer sweets (candy, ice cream, cake, pastries) to my child as a reward for good behavior.

- I withhold sweets/dessert from my child in response to bad behavior.

\section{INDIVIDUAL ITEMS FROM CFPQ SUBSCALE:}

\section{$\underline{\text { Environment }}$}

- Most of the food I keep in the house is healthy.

\section{Pressure to Eat}

- My child should always eat all of the food on his/her plate 


\section{APPENDIX P}

\section{ITEMS FROM THE HCHF-BC BY CONSTRUCT}

\section{Parent Diet \& Activity}

- How many days each week do you usually eat fruit (including fresh, dried, frozen, and canned)?

- How many days each week do you usually eat vegetables (including fresh, frozen, and canned)?

- How often do you drink regular (NOT diet) soda?

- How often do you use $1 \%$ milk, skim milk, or low-fat yogurt?

- How often are you physically active for at least 30 minutes a day - active enough that you breathe a little harder or your heart beats faster? This includes brisk walking, dancing, and playing actively with kids.

\section{Child Diet \& Activity}

- How many days each week do your children usually eat vegetables (including fresh, frozen, and canned)?

- How many days each week do your children usually eat fruit (including fresh, dried, frozen, and canned)?

- How often do your children drink regular (NOT diet) soda?

- How often do your children have $1 \%$ milk, skim milk, or low-fat yogurt?

- How often do your children play actively for at least 60 minutes a day -- actively enough that they breathe a little harder or their hearts beat faster?

- How much time do your children spend watching TV, using the computer, or playing video games?

\section{Parenting \& Home Environment}

- In a typical week, how often do you let your children decide how much food to eat?

- How often do you eat together with your children at least one meal a day?

- In a typical month, how often are high-fat or high-sugar snacks available at home for your children to eat? This includes chips, candy, cookies, and sweets.

- In a typical month, how often are fruits available at home for your children to eat?

- How often do your children usually eat take out, delivery, or fast foods (such as burgers, fried chicken, pizza, Chinese food)? 